Review Article

\title{
Four Forgotten Giants of Anesthesia History
}

\author{
Lewis S. Coleman*
}

Department of Anesthesia, Fellow, American Institute of Stress

*Corresponding author: Lewis S. Coleman, MD, DABA, Department of Anesthesia, Fellow, American Institute of Stress, Tel: 5598023375/(661) 900-2390; E-mail: lewis_coleman@yahoo.com

\begin{abstract}
The anesthesiology profession may one day serve as a cautionary tale of how power, politics and privilege can perturb science and progress. Previous anesthesia practitioners possessed a superior understanding of physiology and pharmacology, but overenthusiastic $\mathrm{CO}_{2}$ supplementation with inadequate monitors and machines caused asphyxiation disasters that were improperly attributed to $\mathrm{CO}_{2}$ toxicity. Dr. Ralph Waters founded the anesthesiology profession on the basis of a practical new anesthetic technique that introduced elective intubation and hyperventilation to eliminate $\mathrm{CO}_{2}$ toxicity, but mechanical hyperventilation dangerously depletes $\mathrm{CO}_{2}$ tissue reserves and exaggerates morbidity and mortality. The benefits of $\mathrm{CO}_{2}$ supplementation were forgotten, and consequent $\mathrm{CO}_{2}$ confusion has derailed research, discouraged opioid treatment, damaged patient safety, and disrupted professional progress. Anesthesiologists can no longer claim to provide superior service, and hospital administrators are replacing them with nurses. Professional membership is in decline, and professional survival is in question. Modern machines have eliminated asphyxiation, and modern monitoring enables safe and beneficial hypercarbia that complements opioid treatment and minimizes surgical morbidity and mortality. $\mathrm{CO}_{2}$ reform promises revolutionary advance but faces formidable opposition.
\end{abstract}

Received date: August 07, 2015

Accepted date: January 16, 2016

Published date: January 21, 2016

Citation: Coleman, L.S. Four Forgotten Giants of Anesthesia History. (2016) J Anesth Surg 3(1): 68-84.

DOI: $10.15436 / 2377-1364.16 .468$

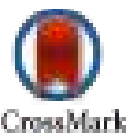

Keywords: Anesthesia theory; Carbon dioxide toxicity; Carbon dioxide narcosis; Opioid; Hyperventilation; Hypoventilation; Asphyxiation; Hypercarbia; Hypocarbia; Permissive hypercarbia; Acidosis; Alkalosis; Hypoxia; Capnography; Capnograph.

\section{Introduction}

Does wisdom perhaps appear on the earth as a raven, which is inspired by the smell of carrion? --Friedrich Nietzsche

Past is prologue. Carbon dioxide confusion has played a pivotal role in the evolution of modern anesthesia. Professional anesthesiology organizations have persistently neglected $\mathrm{CO}_{2}$ management standards in favor of lesser issues ${ }^{[1-4]}$, so that the anesthesiology profession remains mired at the crossroads of revolutionary advance and ongoing self-destruction that can only be understood in historical context. Dr. Ralph Waters founded the profession on the basis of a practical new technique that introduced elective intubation and hyperventilation to abolish $\mathrm{CO}_{2}$ toxicity disasters, but the harmful habit of hyperventilation has distorted anesthesia beliefs, habits, and practices; derailed research; halted professional advance; discouraged opioid treatment; abolished the therapeutic benefits of $\mathrm{CO}_{2}$; exaggerated morbidity and mortality; and introduced a host of vexing clinical problems. It has indirectly fostered the fiction that further improvements in anesthesia safety are impossible, which has undermined reimbursement, emasculated staff privileges, devastated morale, discouraged professional membership ${ }^{\mathrm{A}}$, and rationalized the replacement of anesthesiologists by nurses.

Meanwhile, the confusing chemistry, physiology, and pathology of carbon dioxide have yielded their secrets, modern anesthesia machines have eliminated the toxicity problem, modern agents have eliminated explosions, and modern monitoring

${ }^{\mathrm{A}} \mathrm{WwW}$. anesthesiologynews.com/PrintArticle.aspx?A_Id=30903\&D_Id=449\&D=Commentary

Copy rights: (C) 2016 Coleman, L.S. This is an Open access article distributed under the terms of Creative Commons Attribution 4.0 International License. 
enables safe and beneficial hypercarbia. Recent research, critical care advances, and historical experience have all demonstrated the benefits of hypercarbia and its complementary relationship with opioid analgesia ${ }^{[5]}$. The restoration of past principles using modern capnography, pulse oximetry, synthetic opioids, and improved inhalation agents promises to re-revolutionize surgical safety. This essay will review pertinent elements of $\mathrm{CO}_{2}$ confusion, chemistry, physiology, pathology, mythology, and history to explain how present problems evolved, and why $\mathrm{CO}_{2}$ standards are essential to restore professional progress and prestige, improve surgical safety and efficiency, preserve the profession, and facilitate future advance ${ }^{[1-3]}$.

\section{The Myth of $\mathrm{CO}_{2}$ Toxic and Anesthetic Effects}

$\mathrm{CO}_{2}$ confusion is hardly confined to anesthesia practice. Antiquated SCUBA literature ${ }^{\mathrm{B}}$, arbitrary air quality standards ${ }^{\mathrm{C}}$, the scientifically unfounded panic that followed the Apollo 13 disaster ${ }^{\mathrm{D}}$, and global warming myths ${ }^{\mathrm{E}}$ exemplify endemic cultural fear of $\mathrm{CO}_{2}$ that can be traced to the earliest days of gas research, when the effects of different gases were often confused with one another ${ }^{[6]}$. Lavoisier inadvertently exaggerated $\mathrm{CO}_{2}$ confusion when he contrasted the suffocating effects of $\mathrm{CO}_{2}$ with the life-sustaining properties of oxygen ${ }^{[7]}$. As modern anesthesia evolved during the first half of the previous century, circus sideshows and early anesthesia machine manufacturers provided public demonstrations of carbon dioxide anesthesia ${ }^{[8]}$. However, the $\mathrm{CO}_{2}$ toxicity disasters that occurred during the early days of modern anesthesia are probably the most important source of present fears ${ }^{[9]}$.

The notion that $\mathrm{CO}_{2}$ has anesthetic characteristics originated with the 1823 experiments of Henry Hill Hickman, a British physician who is presently remembered as a father of anesthesia ${ }^{\mathrm{F}}$. He might better be remembered as the first physician to confuse asphyxiation with anesthesia. He suffocated animals with carbon dioxide until they collapsed, and then subjected them to surgery. Several of the animals suffered seizures, and some of them died, but since they didn't move during the procedures, and most of them recovered, he presumed that he had discovered a practical means to prevent surgical pain. His British contemporaries ridiculed his report as "humbug," and he suffered similar skepticism in France. He died young, and some believe that he died of suicide. Modern anesthesia researchers, reviewers, and editors have persistently accepted Hickman's report as proof that $\mathrm{CO}_{2}$ has anesthetic properties ${ }^{[10-12] \mathrm{HI}}$ even though it has always been obvious that his observations were caused by asphyxiation. This can best be understood in the context of anesthesia history.

The source of $\mathrm{CO}_{2}$ : Most theories of the origin of life focus on the earth's surface, but the simplest explanation is that life originated deep beneath the earth's surface, where the unceasing nuclear reaction at the earth's core continuously generates energy rich chemicals and maintains stable hot temperatures. In this nurturing environment, life began spontaneously in the form of chemical reactions that utilized energy rich substances in their surroundings to become self-sustaining, and subsequently devel-

Bhttp://www.scuba-doc.com/CO retention.html

Chttp://www.healthyfacilitiesinstitute.com/a_43-Why_Measure_Carbon_

Dioxide Inside Buildings

Dhttps://answers.yahoo.com/question/index?qid=20060623085913AAo $\mathrm{SnHc}$

Ehttp://www.ehow.com/list_5921485_effects-carbon-dioxide-air-pollution. oped surrounding walls and chemical information systems that enhanced their survival. The unceasing activity of the resulting vast, diverse biomass of subterranean unicellular life forms produced water that formed the oceans, gases that formed the atmosphere, and inexhaustible supplies of oil, and thus set the stage for the development of multicellular life forms that thrive on the earth's surface. Atmospheric gases thus exist in a stable equilibrium of entropy, gravity, and microbial replenishment. This explains why volcanic activity typically releases vast quantities of carbon dioxide into the earth's atmosphere.

The legend of $\mathrm{CO}_{2}$ heaviness: Spelunkers commonly assume that gravity causes asphyxiating accumulations of $\mathrm{CO}_{2}$ in caves, but the actual cause is organic activity that generates $\mathrm{CO}_{2}$ faster than it dissipates from the cave ${ }^{[13]}$. There is a slight "layering effect" in atmospheric gases due to differences in molecular weight, so that hydrogen predominates at extreme altitudes, and most carbon dioxide is found near the earth's surface. This consideration is unimportant at sea level, but it becomes significant in the "Dead Zone" of Mt. Everest, where the low partial pressures of oxygen and $\mathrm{CO}_{2}$ are incompatible with life.

$\mathrm{CO}_{2}$ and respiratory physiology: $\mathrm{CO}_{2}$ is essential for mammalian tissue oxygenation. All eukaryotic cells continuously consume oxygen and glucose and generate $\mathrm{CO}_{2}$, water and ATP via the Krebs cycle. The $\mathrm{CO}_{2}$ accumulates and equilibrates with the ambient atmosphere, so that there are about 20 liters of $\mathrm{CO}_{2}$ dissolved in whole body tissues, compared to one liter of oxygen and one liter of nitrogen gas ${ }^{[14,15]}$. These high levels of $\mathrm{CO}_{2}$ are necessary to release oxygen from the hemoglobin molecule via the Bohr effect to enable oxygen delivery to tissues. Hyperventilation depletes $\mathrm{CO}_{2}$ tissue reserves, inhibits oxygen release from hemoglobin receptor sites, and undermines tissue oxygen delivery.

$\mathrm{CO}_{2}$ also maintains tissue oxygenation by stimulating respiratory drive. It directly activates respiratory chemoreceptors in extravascular tissues, which gradually adapt to the $\mathrm{CO}_{2}$ equilibrium and seek to maintain it. Hyperventilation depletes $\mathrm{CO}_{2}$ tissue reserves and paralyzes the chemoreceptors.

$\mathrm{CO}_{2}$ reversibly interacts with water to form carbonic acid, which harmlessly reduces blood $\mathrm{pH}$ and stimulates $\mathrm{pH}$ sensors in brain ventricles that activate the respiratory drive of consciousness. Normal sleep and anesthesia extinguish consciousness and inactivate this normally dominant form of respiratory drive, whereupon breathing becomes totally dependent upon respiratory chemoreceptors ${ }^{[16-21]}$.

Hypercarbia stimulates both forms of respiratory drive. Hyperventilation combined with loss of consciousness paralyzes both forms of respiratory drive and threatens lethal respiratory arrest.

The following examples illustrate the insidious dangers of $\mathrm{CO}_{2}$ depletion:

1. Every year healthy young swimmers succumb to "Shallow Water Blackout Syndrome"J after they voluntarily hyperventilate themselves before swimming underwater. This depletes

\section{html}

Fhttp://en.wikipedia.org/wiki/Henry_Hill_Hickman

Ghttp://bja.oxfordjournals.org/content/95/6/842.full

${ }^{\mathrm{H}} \mathrm{http}$ //en.wikipedia.org/wiki/Asphyxiant_gas

Ihttp://en.wikipedia.org/wiki/Henry Hill Hickman

Jhttp://en.wikipedia.org/wiki/Shallow_water_blackout 
$\mathrm{CO}_{2}$ tissue reserves, but does not enhance oxygen reserves. The swimmer becomes mildly hypoxemic, which causes painless euphoria, bad judgment, and sleepiness, while respiratory drive remains obtunded by $\mathrm{CO}_{2}$ depletion, so that the swimmer falls asleep and drowns.

2. Mechanical hyperventilation depletes $\mathrm{CO}_{2}$ tissue reserves and paralyzes chemoreceptors during general anesthesia. Hyperventilated patients appear to breathe normally after anesthetic emergence, but their respiratory drive remains unstable until metabolic activity restores $\mathrm{CO}_{2}$ tissue reserves. This may require several hours in geriatric patients with low metabolic rates. If the patient falls asleep for any reason during this vulnerable period, he may stop breathing and suffer brain damage or death ${ }^{[3,4]}$.

3. Hyperventilation during general anesthesia for cesarean section depletes $\mathrm{CO}_{2}$ reserves of babies as well as mothers. This causes newborn babies to unexpectedly fall asleep, stop breathing, and die after uneventful delivery ${ }^{[22]}$.

4. While testing prototype capnograph equipment, Hewlett Packard engineers discovered that healthy young polio victims were being hyperventilated in iron lung machines. Morbidity and mortality fell in half when this was corrected ${ }^{[24]}$.

5. $\mathrm{CO}_{2}$ depletion during ECMO (Extra Corporeal Membrane Oxygenation) exaggerates morbidity and mortality ${ }^{[24,25]}$.

6. Hypoxemic hyperventilation in the "dead zone" near the top of Mt. Everest depletes $\mathrm{CO}_{2}$ tissue reserves, decreases brain perfusion and oxygenation, damages brain tissue, and causes unexpected loss of consciousness ${ }^{[26]}$.

7. Hyperventilation has been abandoned as a treatment for head injuries, because it inhibits brain perfusion, invites lethal rebound brain swelling, and undermines outcome ${ }^{[26,27]}$

\section{Asphyxiation, Hypoxemia, Hypoxia, and ATP}

Asphyxiation is insufficient oxygen in the body due to inadequate breathing. It causes hypoxemia, which is inadequate oxygen in the blood. Hypoxemia causes hypoxia, which is inadequate oxygen in cells and tissues. All eukaryotic cells require a continuous supply of oxygen to enable the Krebs cycle that generates 38 molecules of ATP for every molecule of glucose consumed $^{\mathrm{K}}$. ATP energizes all cell activities. Hypoxia inhibits the Krebs cycle and undermines ATP generation, which primarily affects nervous and muscular activities that require large amounts of ATP. Hypoxia thus undermines cell activity, which mimics toxicity but causes no cell damage short of hypoxic cell death. In contrast, mustard gas and other toxic agents chemically interact with cells and tissues, causing tissue damage and cell death.

Mild hypoxia causes fatigue, muscle weakness, numbness, tingling, nausea, ataxia, confusion, disorientation, hallucinations, behavioral changes, poor judgment, impaired consciousness, breathlessness, tachycardia, and papilledema ${ }^{[28,29] \mathrm{L}}$.

Moderate hypoxia causes reversible loss of consciousness that mimics general anesthesia. Depending on duration and degree, hypoxic unconsciousness can be maintained in mammals for prolonged periods of time without causing overt damage, and is readily reversed by restoring oxygen to cells.
Prolonged, severe hypoxia mimics surgical grade anesthesia by inhibiting nervous reflexes. It also causes cyanosis, bradycardia, cor pulmonale, low blood pressure, convulsions, cellular anaerobic metabolism that generates lactic acid (metabolic acidosis), brain damage, and death.

\section{$\mathrm{CO}_{2}$ asphyxiation}

Cardiopulmonary physiology normally maintains $\mathrm{CO}_{2}$ concentrations in the lung around $5 \%$, and lung physiology efficiently expels $\mathrm{CO}_{2}$ at ambient atmospheric levels of $0.3 \%$. Inhaling $\mathrm{CO}_{2}$ concentrations above $5 \%$ progressively increases $\mathrm{CO}_{2}$ concentrations within the lung, which displaces oxygen in the lung and undermines oxygen uptake into the blood, causing hypoxemia. This occurs despite oxygen supplementation ${ }^{[30] \mathrm{M}}$ and is one of many forms of asphyxiation ${ }^{\mathrm{N}}$.

Like nitrogen, methane, argon, helium, butane, propane and other Asphyxiant gases, $\mathrm{CO}_{2}$ is odorless, tasteless, colorless and invisible. Unlike other Asphyxiant gases it causes a suffocation sensation that induces fear and warns of its presence.

Humphrey Davey famously inhaled $30 \% \mathrm{CO}_{2}$ with great difficulty, but this reflected his impressive determination ${ }^{[31]}$, because few volunteers can tolerate breathing $\mathrm{CO}_{2}$ at concentrations higher than $10 \%{ }^{[28]}$. The fear of suffocation stimulates sympathetic nervous activity, which elevates blood viscosity, blood coagulability, heart rate, and blood pressure ${ }^{[28,29]}$. This nervous activity mimics toxicity, but toxic tissue damage is absent. Hypercarbia also exaggerates brain perfusion, which probably accounts for headache ${ }^{[32]} \cdot \mathrm{CO}_{2}$ asphyxiation thus mimics toxicity by causing hypoxia, exaggerated brain perfusion, and sympathetic nervous system hyperactivity ${ }^{\mathrm{OP}}$. Anesthetic agents, drug effects, surgical stress, oxygen supplementation, mechanical ventilation, pathology and skin pigmentation in animals can alter or obscure the clinical manifestations of asphyxiation.

$\mathrm{CO}_{2}$, refrigeration, explosion, fire, and asphyxiation: Like Freon, $\mathrm{CO}_{2}$ is a refrigerant gas that absorbs large amounts of heat compared to most other gases when it transitions from liquid to gas. It obeys classical gas laws, but when released from a pressurized tank it temporarily forms a cool, invisible, tasteless, odorless cloud that is affected by gravity, pours like water, fills dependent spaces, and displaces oxygen until it absorbs enough heat to blend with other atmospheric gases ${ }^{\mathrm{Q}}$. Chemists call this a "transition state." These characteristics enable it to retard fires and explosions as well as cause unexpected asphyxiation. ${ }^{\mathrm{RS}}$ During the early days of modern anesthesia, $\mathrm{CO}_{2}$ supplementation from pressurized tanks was used to optimize cardio respiratory function and reduce the risk of ether and cyclopropane explosions, but it sometimes caused unexpected lethal asphyxiation that was mistaken as toxicity.

$\mathrm{CO}_{2}$ asphyxiation versus anesthesia: Inhaling $\mathrm{CO}_{2}$ concentrations below $5 \%$ has minimal effect on consciousness, but above $10 \%$ it causes moderate hypoxia that suddenly abolishes consciousness. This effect mimics general anesthesia, because it can be maintained in mammals for hours and is readily reversed

\footnotetext{
${ }^{\mathrm{P}}$ http://www.generalair.com/pdf/Safety\%20Topics/Carbon\%20Dioxide\%20 Asphyxiation.pdf

Qhttps://www.osha.gov/dts/hib/hib_data/hib19960605.html

${ }^{\mathrm{R}} \mathrm{http}: / /$ www.nafed.org/whyco2

shttps://www.osha.gov/dts/hib/hib_data/hib19960605.html
}

\footnotetext{
Khttp://en.wikipedia.org/wiki/Citric_acid_cycle

Lhttp://en.wikipedia.org/wiki/Hypoxemia

${ }^{\mathrm{M}} \mathrm{http}$ //en.wikipedia.org/wiki/Inert gas asphyxiation

Nhttps://en.wikipedia.org/wiki/Asphyxia

ohttps://www.osha.gov/dts/hib/hib_data/hib19960605.html
} 
without causing overt damage. Inhaling $\mathrm{CO}_{2}$ concentrations above $30 \%$, even with oxygen supplementation, causes severe hypoxia that obtunds nervous reflexes and mimics surgical grade anesthesia, but the margin of safety is narrow, and slightly higher $\mathrm{CO}_{2}$ concentrations can precipitate cellular anaerobic respiration, lactic (metabolic) acidosis, fever, profuse perspiration, cyanosis, convulsions, brain damage, and death ${ }^{[10,33,34]}$.

Anesthesia differs from asphyxiation in several ways. Genuine anesthetic inhalation agents cause progressive toxic inhibition of consciousness (hypnosis), cardiac function, and respiratory drive via unknown mechanisms, but they have a wide margin of safety. They are pleasant to inhale and inherently addictive. They cause additive effects when combined with one another and intravenous hypnotic agents. In contrast, $\mathrm{CO}_{2}$ stimulates respiratory drive and cardiac output. It has no direct effect on brain activity, and does not exaggerate hypnotic agent activity. Breathing $\mathrm{CO}_{2}$ while awake is unpleasant, and $\mathrm{CO}_{2}$ addiction is unknown. $\mathrm{CO}_{2}$ asphyxiation causes sudden loss of consciousness as $\mathrm{FICO}_{2}$ rises above $10 \%$, and becomes lethal at concentrations above $30 \%$.

During anesthesia, hypercarbia produces safe and useful effects in concentrations as high as $10 \%{ }^{[35,36]}$. Anesthesia abolishes the pulmonary discomfort and suffocation sensation that stimulates tachycardia and hypertension, whereupon the direct effects of mild hypercarbia reduce blood viscosity, optimize microcirculatory flow, cardiac efficiency, cardiac output, tissue perfusion, tissue oxygenation, anesthetic induction, respiratory drive, organ function, opioid clearance, and prevent lung damage and opioid respiratory depression ${ }^{[34,35,37-42]}$. Anesthesia simultaneously obscures the clinical warning signs of hypoxia (muscle weakness and disturbed mental function followed by unconsciousness) but these become problematic only when $\mathrm{FICO}_{2}$ exceeds $10 \%$. At $\mathrm{FICO}_{2}$ above $30 \% \mathrm{~m} \mathrm{CO}_{2}$ asphyxiation manifests suddenly and unexpectedly in the form of metabolic acidosis, profuse perspiration, cyanosis, brain convulsions, and death ${ }^{[10,34]} \cdot \mathrm{CO}_{2}$ asphyxiation was mistakenly attributed to $\mathrm{CO}_{2}$ toxicity in the previous century, when capnography and pulse oximetry were unknown, and defective machine designs enabled excessive $\mathrm{CO}_{2}$ elevations.

\section{Respiratory acidosis}

Hypoventilation accumulates $\mathrm{CO}_{2}$ in blood and tissues, causing "respiratory acidosis" that is benign and beneficial in the absence of hypoxia. $\mathrm{CO}_{2}$ enhances the release of oxygen into tissues via the Bohr effect, stimulates respiratory chemoreceptors, reduces blood viscosity, improves cardiac efficiency, and reversibly interacts with water in blood to form harmless carbonic acid that reduces blood $\mathrm{pH}$ and stimulates the respiratory drive of consciousness via $\mathrm{pH}$ receptors in brain ventricles. Harmless hypoventilation occurs during both normal sleep and anesthesia when respiratory drive becomes dependent on respiratory chemoreceptors, causing mild respiratory acidosis that enhances tissue perfusion, tissue oxygenation, and organ function.

\section{Metabolic acidosis}

Several types of metabolic disturbance cause metabolic acidosis. Most are harmless, but some reflect potentially lethal circumstances, so that metabolic acidosis is often regarded as a harbinger of death.

Lactic acidosis occurs when cellular oxygen starvation caus- es cells to revert to anaerobic respiration, which generates lactic acid that harmlessly accumulates in tissues and blood. Such cellular oxygen starvation sometimes occurs during strenuous athletic exercise, causing painful lactic acid accumulation in muscles and tissues. The lactic acid itself is harmless and is readily metabolized by cells after oxygen is restored. However, pathological conditions that disrupt oxygen delivery to cells, including heart failure, myocardial infarction, sepsis, and asphyxiation, can also cause lactic acidosis. Such pathologies can cause severe oxygen starvation that disrupts ATP generation, causing cell dysfunction and cell death.

Ketoacidosis occurs when cellular glucose starvation causes cells to digest tissue protein to generate ATP. This abnormal form of cellular metabolism occurs in prolonged starvation and uncontrolled diabetes. It undermines tissue structure and generates acidic ketone bodies that reduce $\mathrm{pH}$ in blood and tissues. Cells metabolize the harmless ketone bodies, but prolonged starvation and uncontrolled diabetes are potentially lethal.

Intoxication acidosis occurs when toxic drugs and chemicals harmfully disrupt cellular metabolism. These include salicylates, ethanol, methanol, formaldehyde, sulfates, and metformin.

\section{Hypoventilation, hyperventilation, opioids and anesthesia}

Hypercarbia and hyperventilation produce opposite effects during anesthesia, because hypercarbia enhances $\mathrm{CO}_{2}$ tissue reserves, while hyperventilation depletes them, and anesthesia abolishes the suffocation sensation, fear, and increased sympathetic activity induced by hypercarbia in conscious subjects. During anesthesia, mild hypercarbia at least as high as 80 torr enhances microcirculatory flow, reduces blood viscosity, improves cardiorespiratory function, increases tissue oxygenation, accelerates opioid clearance, offsets opioid respiratory depression, prevents lung damage, and protects organ function ${ }^{[34-37]}$. In contrast, hyperventilation increases blood viscosity, undermines cardiorespiratory function, reduces opioid clearance, exaggerates opioid respiratory depression, decreases tissue perfusion, reduces tissue oxygenation, and compromises organ function.

Opioid analgesia inhibits surgical nociception and improves surgical outcome ${ }^{[43-45]}$, but its benefits often escape the notice of anesthesia practitioners because the surgical stress reaction does not reach peak intensity until 48 hours after surgery ${ }^{[46,47]}$. The increased morbidity and mortality persists in the distant aftermath of surgery, mostly in the form of heart disease and cancer ${ }^{[48]}$.

Hyperventilation is incompatible with opioids, because both inhibit respiratory chemoreceptors ${ }^{[5]}$. Furthermore, hyperventilation inhibits opioid metabolism and clearance ${ }^{[37,49,50]}$. Thus effective opioid treatment in the presence of hyperventilation necessitates prolonged and hazardous postoperative "weaning" from mechanical hyperventilation to enable metabolic activity to gradually restore $\mathrm{CO}_{2}$ tissue reserves and chemoreceptor function. In contrast, hypercarbia accelerates opioid clearance, exaggerates respiratory chemoreceptor sensitivity, offsets opioid respiratory depression, and enables practical, safe opioid dosage that effectively controls surgical nociception and enhances outcome ${ }^{[43,44]}$.

If opioid treatment is judiciously minimized, hyperventilated patients appear to breathe normally after anesthetic 
emergence, but their respiratory drive remains unstable until metabolic activity restores $\mathrm{CO}_{2}$ tissue reserves and respiratory chemoreceptor function. During this vulnerable period, which may persist for hours in elderly patients with low metabolic rates, small doses of opioids and sedatives may cause lethal respiratory depression ${ }^{[3,4]}$. The nature of this phenomenon is generally misunderstood, so that it is called the "opioid hypersensitivity syndrome" ${ }^{[3,4]}$.

Within reason, opioids and hypercarbia might be compared to love and marriage. Opioids inhibit respiratory chemoreceptor sensitivity, but hypercarbia stimulates respiratory chemoreceptors and offsets opioid respiratory depression. Mild hypercarbia ( $\mathrm{ETCO}_{2} 50$ torr) preserves $\mathrm{CO}_{2}$ tissue reserves and chemoreceptor function, accelerates opioid clearance, offsets opioid respiratory depression, optimizes cardiac output, cardiac efficiency, tissue perfusion, and tissue oxygenation, and enables enhanced opioid dosage that inhibits surgical nociception and optimizes surgical outcome.

The key to safe opioid management is to avoid opioid reversal agents, and confirm spontaneous breathing prior to anesthetic emergence that affirms respiratory chemoreceptor function. Emergence then restores the primary respiratory drive of consciousness, so that both primary and secondary forms of respiratory drive are restored and the danger of unexpected respiratory depression is eliminated ${ }^{[3,4]}$.

\section{The four forgotten giants of anesthesia}

American medical science was surprisingly sophisticated early in the previous century ${ }^{[14,51]}$. The approaching apocalypse of WWI inspired the founding of Johns Hopkins Medical School, which imported the German model of medical research in 1893, and the Flexner Report reformed American medical education in $1911^{[51]}$. These changes accelerated American medical progress and produced four giants of anesthesia whose seminal contributions are now mostly forgotten.

George Washington Crile, MD (1864-1943) should be remembered as the Father of modern anesthesia. He was famous in his time, but is now rarely remembered as a surgeon who performed the first successful blood transfusion ${ }^{[52]}$. This was perhaps the least of his accomplishments. The lingering death of his best friend in medical school from a streetcar accident inspired his lifelong quest to clarify the cause of shock. He toured Europe to learn the latest medical techniques and became a trauma surgeon, riding to accidents on horseback. He married the niece of Mark Hanna, the most powerful American political figure of the time. He was appalled by war but served as a medical officer in both the Spanish-American War and World War ${ }^{[53-55]}$.

Crile's career was legendary. He built a laboratory with his own funds and performed extensive animal research. He invented cardiopulmonary resuscitation and demonstrated the utility of epinephrine ${ }^{[56,57]}$; introduced blood pressure and pulse rate monitoring during surgery; investigated the effects of anesthesia on acidosis ${ }^{[58,59]}$; demonstrated that blood transfusion effectively treats shock, but crystalloids are useless and potentially harmful; showed that pain, fear, and apprehension undermine surgical outcome; introduced pre-medication, early admission, and delayed discharge to optimize surgical outcome; designed and installed sophisticated anesthesia machinery; and established the first nurse anesthesia training school ${ }^{[60,61]}$ Most pertinent to this paper, he recognized that occult nervous stimulation causes or exaggerates shock. He demonstrated that massive doses of morphine effectively treat septic shock and peritonitis, and that analgesia improves surgical outcome when it is added to general anesthesia. His book "Anoci-Association" describes how he used morphine and prilocaine infiltration to complement anesthesia, and is arguably more pertinent today than when it was published $^{[45]}$.

Yandell Henderson, PhD (1873-1944) was the director of the Yale laboratory of applied physiology and the most prominent gas physiologist in his era. Like Crile, he was an idealist who believed that science should serve the public interest ${ }^{[62]}$. He opposed American involvement in $\mathrm{WWI}^{\mathrm{T}}$. He testified before congress about the dangers of automobile exhaust pollution, though his views were not accepted until long after his death ${ }^{[63]}$.

In 1911 Henderson famously led a team of international experts that studied respiratory physiology at the top of Pike's Peak ${ }^{[64]}$. His research demonstrated that spontaneous hyperventilation during anesthesia (due to inadequately controlled surgical stimulation) can cause cardiopulmonary collapse or unexpected postoperative respiratory arrest. He showed how $\mathrm{CO}_{2}$ supplementation stabilizes hemodynamic function, stimulates respiratory drive, enhances cardiac efficiency, improves tissue oxygenation, and prevents postoperative atelectasis, pneumonia, nausea, vomiting, and unexpected respiratory arrest ${ }^{[30,65,66]}$. Henderson also demonstrated that $\mathrm{CO}_{2}$ supplementation effectively treats myocardial infarction, angina, strokes, pneumonia, asthma, influenza, breathing problems in newborn babies, carbon monoxide poisoning, drowning, and smoke inhalation ${ }^{[30,67,68]}$. His work inspired the installation of Carbogen ${ }^{\mathrm{U}}$, which was a mixture of oxygen and carbon dioxide, on fire trucks in New York City, Chicago, and other major cities. Carbogen was widely embraced by physicians as an effective treatment, and it was credited with saving many lives, but unfounded fears of $\mathrm{CO}_{2}$ toxicity caused it to disappear from use.

In 1912 Dr. Henderson chaired a five-member Committee on Anesthesia that reported to the American Medical Association's House of Delegates. It forcefully stated:"Anesthesia should cease to be regarded as merely an adjunct of surgery. It should be in charge of those whose principal aim is, not to see as much of the operation as possible, but to administer anesthesia in such a manner as to bring the patient through with the least possible loss of vitality." Coming just two years after the Flexner Report, this recommendation had little effect on anesthesia practice, but it did put the AMA on record as supporting improvement in anesthesia practice $\mathrm{V}$.

Dennis Jackson (1878-1980) was a pharmacist. The onerous cost of medical gases inspired him to invent closed circuit circle system anesthesia machines that became the precursors of modern anesthesia machines. He built his own workshop and tested his prototypes on his pet dogs. Jackson's machines quickly supplanted competing machines because they minimized gas waste,
${ }^{\mathrm{T}}$ http://www.nasonline.org/publications/biographical-memoirs/memoir-pdfs/henderson-yandell.pdf
Uhttps://en.wikipedia.org/wiki/Carbogen

vA.J. Wright "Appeals for Physician Anesthesia in the United States between 1880 and 1920 
reduced explosion hazards, and enabled respiratory assistance. Jackson's closed circuit machines minimized gas waste because the patients re-breathed the gas mixtures within the machines, and oxygen was added only as needed to replace consumption. Milk bottles filled with liquid sodium hydroxide absorbed carbon dioxide in early machines. An electric motor forced the gas mixture through the liquid sodium hydroxide. Fortunately these motors never caused an ether explosion. Soda lime soon supplanted the motors and milk bottles ${ }^{[69]}$.

John Silas Lundy, MD (1894-1973) was chairman of the anesthesia department at the Mayo Clinic. He established an early anesthesia-training program. He trained Dr. Ralph Waters and helped him establish the anesthesiology profession. He introduced intravenous barbiturate induction, ventilators, ventilator vests, oxygen tents, and nasal oxygen. He demonstrated that $\mathrm{CO}_{2}$ supplementation accelerates ether induction ${ }^{[70]}$. He developed anesthesia machines, needles and syringes for spinal anesthesia, and the concept of balanced anesthesia. He established the first blood bank, the first anatomy lab, and the first recovery room. He produced numerous papers and a textbook of anesthesia.

\section{The Crile/Henderson Anesthesia Technique}

Early anesthetists faced forgotten difficulties. Their inhalation agents were smelly, slow, and explosive. Most cases were managed by mask with spontaneous breathing, because IV access was lacking and intubation remained tedious and time-consuming. They quickly embraced Jackson's anesthesia machines and the research of Crile, Henderson and Lundy to evolve a sophisticated anesthetic technique that combined ether anesthesia and morphine analgesia with $\mathrm{CO}_{2}$ supplementation. They used intramuscular morphine to mitigate preoperative anxiety and pain, obtund the obnoxious odor of ether, prevent intraoperative tachycardia, hypertension, untoward movements, and muscle tension, and minimize postoperative morbidity, mortality, and pain. They used $\mathrm{CO}_{2}$ supplementation to stimulate breathing, offset morphine respiratory depression, optimize morphine dosage, accelerate ether induction and emergence, enhance cardiac efficiency, promote tissue perfusion and oxygenation, reduce the risk of gas explosion, and prevent postoperative nausea, vomiting, respiratory depression, atelectasis, and pneumonia. They added bypass valves to Jackson's closed circuit anesthesia machines to isolate soda lime from the breathing circuit and accelerate $\mathrm{CO}_{2}$ accumulation within the machines. They also added external $\mathrm{CO}_{2}$ tanks for $\mathrm{CO}_{2}$ supplementation.

Shortcomings of the Crile/Henderson Technique: The Crile/ Henderson balanced anesthesia technique produced superior surgical stress control and outcome, but suffered significant shortcomings. Intubation was difficult without muscle relaxants, and muscle tension was problematic. Many types of surgery were impossible without intubation, and there was constant threat of airway obstruction, laryngospasm, vomiting, and aspiration. The most dramatic problem was overenthusiastic $\mathrm{CO}_{2}$ supplementation that occasionally caused unexpected $\mathrm{CO}_{2}$ asphyxiation disasters. Patients would unexpectedly develop fever, profuse perspiration, convulsions, and cyanosis, often succeeded by death.

${ }^{\mathrm{w}} \mathrm{http}: / /$ asevet.com/resources/circuits/waters.htm

${ }^{\mathrm{x}}$ http://anesthesia.wisc.edu/index.php?title=RMWVP_Biography
Without capnography or pulse oximetry, there was no warning. The baffling Dr. Jekyll/Mr. Hyde nature of this phenomenon was initially attributed to fever or occult medical problems ${ }^{[71,72]}$. The causative role of $\mathrm{CO}_{2}$ was soon recognized ${ }^{[73]}$, but practitioners were reluctant to abandon the utility of $\mathrm{CO}_{2}$ supplementation. Perhaps the most compelling reason, now forgotten, is that $\mathrm{CO}_{2}$ supplementation minimized ether and cyclopropane explosions.

\section{The founding of Professional Anesthesiology}

Dr. Ralph Waters (1883-1979) founded the anesthesiology profession. He attended Case Western Reserve medical school during the era of George Washington Crile. He established a busy outpatient surgery clinic in Iowa, where he specialized in anesthesia and obstetrics, but he soon abandoned obstetrics to concentrate on anesthesia. He left private practice for three years to study regional anesthesia with Dr. John Lundy at the Mayo Clinic. He played a prominent role in early professional progress. He worked with Arthur Gudel to develop the cuffed endotracheal tube and demonstrated its utility at professional meetings by plunging his anesthetized pet dog "Airway" into a tank of water. He introduced endobronchial anesthesia and cyclopropane. He researched $\mathrm{CO}_{2}$ absorbance and helped to introduce soda lime ${ }^{[74,75]}$. He introduced the Waters canister ${ }^{\mathrm{W}}$ that provided a simple and efficient means to conserve expensive anesthetic gases and prevent $\mathrm{CO}_{2}$ accumulation. His determination to establish anesthesiology as an independent medical specialty can be traced to 1919, when he published an essay entitled "Why the Professional Anesthesiologist?"X

In 1897 Dr. Charles Russell Bardeen ${ }^{\mathrm{Y}}$ became the first student to receive an MD degree from Johns Hopkins Medical School. In 1907 he became the Dean of the University of Wisconsin medical school. In 1927 he recruited Dr. Waters to become the first chairman of a university anesthesia department in the world. Barton later said, "Ralph Waters was the first person the University hired to put people to sleep, but, instead, he awakened a worldwide interest in anesthesia."

Shortly before he arrived at Wisconsin ${ }^{\mathrm{Z}}$, Dr. Waters published the first of four papers that ultimately altered medical beliefs, habits, standards, and practices throughout the world. The papers focused on confusing $\mathrm{CO}_{2}$ effects at a time when circus sideshows and early anesthesia machine manufacturers gave public demonstrations of " $\mathrm{CO}_{2}$ anesthesia." Many physicians believed that $\mathrm{CO}_{2}$ possessed both toxic and narcotic properties, and that acid/base imbalance was harmful ${ }^{[28]}$. Nevertheless they commonly utilized Carbogen, which was a mixture of oxygen and carbon dioxide, to treat numerous medical conditions, while anesthetists embraced $\mathrm{CO}_{2}$ supplementation. One forgotten consideration is that is that $\mathrm{CO}_{2}$ was a cheap and readily available waste product of oil processing in an era when medical gases such as oxygen and nitrous oxide remained so expensive as to be unaffordable for middle class people, and government support for medical care was lacking ${ }^{[69]}$.

Dr. Waters consistently characterized carbon dioxide as a "toxic waste product, like urine" and emphasized its problematic properties. He never conceded any $\mathrm{CO}_{2}$ benefits or entertained any possibility $\mathrm{CO}_{2}$ asphyxiation ${ }^{[14]}$. His influence relegated Carbogen and carbon dioxide to the dustbin of medical

${ }^{Y}$ http://en.wikipedia.org/wiki/Charles_Russell_Bardeen

${ }^{z}$ Occam's Razor, the most fundamental principle of science, states that the simplest explanation is most likely correct. 
history.

\section{The First Paper:" Carbon Dioxide: Its Place In Anes- thesia"}

In the first of his carbon dioxide papers ${ }^{[8]}$, Dr. Waters praised Hickman's "careful animal experiments" as proof that $\mathrm{CO}_{2}$ has anesthetic effects, and ignored the criticisms of Hickman's British and French contemporaries. From a modern perspective this seems unjustified, because Hickman obviously suffocated his animals with $100 \% \mathrm{CO}_{2}$, and the concept of asphyxiation was well understood in Waters' time ${ }^{[56]}$. Dr. Waters arbitrarily attributed tachycardia, hypertension, and blood hypercoagulability to $\mathrm{CO}_{2}$ toxicity. He cited public demonstrations of " $\mathrm{CO}_{2}$ anesthesia" as evidence of $\mathrm{CO}_{2}$ narcotic effects, but from a modern perspective it is obvious that these effects were due to partial asphyxiation. He incorrectly attributed corn silo poisoning, which is caused by methane asphyxiation, to $\mathrm{CO}_{2}$ toxicity. He attacked Yandell Henderson's $\mathrm{CO}_{2}$ research:

"Fortunately, and unfortunately, the researches in carbon dioxide of the New Haven school of physiologists (i.e. Yandell Henderson) have entered the literature of anesthesia in the past decade: fortunately because these researches are brilliant and have taught us many facts of the greatest importance; unfortunately, because the facts have been made use of by practical anesthetists in some quarters to make easy their work without sufficient investigation as to what by-effects may accompany the altered physiology which their methods induce. ------ Let us not allow the spectacular results of "stunt flying" in anesthesia to make us forget----sound principles. The mere fact that anesthesia can be more quickly and conveniently induced and terminated by the use of carbon dioxide is not sufficient ground for administering that gas."

At the end of his paper, Dr. Waters offered the following conclusions:

"1. Changing the amount of carbon dioxide inspired by sick patients is interfering with fundamental physiology and should not be undertaken lightly.

2. The use of carbon dioxide by the anesthetist probably can be put on a rational basis.

3. Until more knowledge is available, conservatism in the use of carbon dioxide by the anesthetist should be practiced."

\section{The Second Paper: "The Anesthetic Properties Of Car- bon Dioxide"}

Soon after he arrived at Wisconsin, Dr. Waters performed animal experiments with the help of Dr. Chauncey Leake, the Chairman of the Pharmacology Department, who had gained academic prominence due to his war gas research ${ }^{[12]}$ These were similar to Hickman's experiments 100 years earlier, except that Waters and Leake employed mixtures of $\mathrm{CO}_{2}$ and oxygen instead of pure carbon dioxide. They lacked the means to monitor blood gas levels, and they judged anesthetic effects on the basis of crude clinical observations, as per the custom of their time. They probably employed Carbogen mixtures, which were readily available in that era. They failed to consider that animals do not ordinarily exhibit cyanosis in the presence of hypoxia, because of tissue pigmentation. They summarized their observations as follows:
"Aside from Hickman's effort a century ago, and the neglected records of B.W. Richardson, little significance has been reported on the anesthetic powers of carbon dioxide. We have found that 30 to 50 percent carbon dioxide with oxygen will anesthetize rabbits in about a minute's time, without apparently causing much excitement, and usually without struggling. Placed in chambers to which such a mixture is supplied, these animals will move about sniffing and breathing more deeply than usual. Muscular activity is gradually depressed and, when anesthesia comes on, muscular relaxation is marked. At this time the respiration is much deeper, but the rate is about the same as normally. Upon removal from the chamber into a normal atmosphere, recovery is prompt and apparently without after-effect."

Leake and Waters mistakenly assumed that asphyxiation was impossible in the presence of oxygen concentrations at least twice as high as atmospheric air. They ignored contemporary evidence that $\mathrm{CO} 2$ asphyxiation mimics general anesthesia and causes cyanosis at concentrations as low as $10 \%{ }^{[14,28]}$. Many years later Dr. Leakey documented this mistake in an interview at UC San Francisco:

"Well, in 1828, Henry Hill Hickman, in England, had reported on the anesthetic properties of carbon dioxide. Nobody had ever looked at it since that time, so Ralph Waters and I thought, well, we ought to take a look at it, and see if he was right. So a hundred years later, 1928, we did put out a report on carbon dioxide as an anesthetic agent. It is 30\% carbon dioxide and seventy percent oxygen, so there is no possibility of asphyxiation; that is anesthetic. One can maintain, as we did, animals, dogs, rabbits, and so on, eight and ten hours in carbon dioxide anesthesia without any difficulty at all. There is always a little trouble when they go over, a little neck jerking and so on. We tried it in humans but decided not to use it because it upset the surgeons, and all; the animals' neck muscles would twitch; but that would be over pretty quickly. We never had guts enough to hold it in humans. This would be fully physiological: I haven't any idea how on earth it works. Nobody knows how anesthetic agents work, as yet; there are all kinds of theories." $\mathrm{AA}$

\section{3 the Third Paper: "The Toxic Effects Of Carbon Dioxide"}

Based on extensive animal experiments, Dr. Henderson had recommended $5 \% \mathrm{CO}_{2}$ supplementation during anesthesia to prevent postoperative respiratory depression, atelectasis and nausea, but practicing anesthetists quickly embraced mixtures of $25 \% \mathrm{CO}_{2}$ and $75 \% \mathrm{O}_{2}$ that produced superior clinical results $^{[30,76,77]}$. Reports of mysterious convulsions and deaths during anesthesia soon appeared ${ }^{[71]}$, but these disasters were initially attributed to fever and occult medical problems ${ }^{[72,73]}$. Dr. Waters believed that $\mathrm{CO}_{2}$ toxicity caused these disasters, and this inspired his third $\mathrm{CO}_{2}$ paper.

Soon after his animal experiments, Dr. Waters attempted $\mathrm{CO}_{2}$ anesthesia on patients. This experience may explain why he became one of the first to appreciate the dangers of $\mathrm{CO}_{2}$ supplementation, and in 1933 he published a third paper entitled "The Toxic Effects of Carbon Dioxide"[9] in which he cited several examples as evidence of $\mathrm{CO}_{2}$ toxicity. However, all his examples reflected $\mathrm{CO}_{2}$ asphyxiation and nervous stimulation rather than toxicity.

AA http://www.woodlibrarymuseum.org/library/pdf/W0071.pdf (page 34) 
Dr. Waters' first cited the volcanic Grotto del Cane (aka "Dog's Cave") near Naples, Italy that has been known since antiquity. ${ }^{\mathrm{BB}}$ The Grotto del Cane is not a cave, but rather a small passage where a volcanic fumarole produces a continuous discharge of carbon dioxide that forms an invisible lake of asphyxiating $\mathrm{CO}_{2}$ in the depressed floor of the passage. People walking through the passage are not affected because their heads remain above the lake of $\mathrm{CO} 2$, but dogs were drowned in the $\mathrm{CO}_{2}$ and quickly became unconscious. To impress tourists, the same dogs were repeatedly exposed to the $\mathrm{CO}_{2}$ without harm, which reflects the absence of $\mathrm{CO}_{2}$ toxicity. A toxic agent, such as mustard gas, would produce persisting harm.

Next, Dr. Waters quoted this dramatic description of the $\mathrm{CO}_{2}$ toxicity syndrome provided by an anonymous practitioner:

"The patient was a well developed girl of fifteen who entered the hospital with a chief complaint of tenderness localized at McBurney's point. Her temperature was 101.8 F.; her pulse was about 85, and respirations 20. Chest examination was negative. An appendectomy was advised. To produce anesthesia, I employed nitrous oxide induction followed by ether, with the absorption technique ${ }^{C C}$. The machine did not absorb carbon dioxide very well at any time. The anesthesia was well established with ether, and the operation begun, the patient having excellent color, respirations about 26, pulse 90, pupils small and extrinsic muscles of the eyeball paralyzed, when she began to have small constant twitchings of the face. A short time later there appeared a small clonic body convulsion. I thought of anoxemia as a cause even though respirations were not depressed, pupils small, pulse good and color good. Oxygen was administered, ether was deepened, then abandoned, then reapplied and various other procedures tried in an attempt to relieve the situation. These efforts included giving a lot of carbon dioxide because of possible alkalosis. The convulsions continued, getting steadily more violent, her pulse rose to 120, and her temperature obviously increased. $A$ half hour after the onset of the convulsions, she died. This case has been widely discussed among our hospital staff members, and no adequate explanation offered. The surgeon says it was a case of too much ether, our anesthetic technician believes it to have been anoxemia, and the pathology department, after a complete postmortem examination including the brain, concluded that it must have been asphyxia, largely because of the essentially normal findings."

This disturbing account illustrates the confusing "Dr. Jekyll/Mr. Hyde" nature of $\mathrm{CO}_{2}$ asphyxiation during general anesthesia, but it does not prove $\mathrm{CO}_{2}$ toxicity. Asphyxiation explains the reported symptoms. Interestingly, the anesthetist was concerned during the crux of the crisis that spontaneous hyperventilation might cause respiratory alkalosis, which was then regarded as harmful. Therefore he administered additional supplements of carbon dioxide to correct the alkalosis. This exaggerated the asphyxiation and doomed the patient. His actions reflected Henderson's recommendation that $\mathrm{CO}_{2}$ supplementation be used to offset the harmful alkalosis induced by spontaneous hyperventilation due to uncontrolled surgical stimulation, and thereby prevent postoperative respiratory arrest, atelectasis,

${ }^{\text {BB }}$ http://www.showcaves.com/English/it/caves/Cane.html

${ }^{C C}$ The "absorption technique" refers to the use of soda lime to absorb car- and pneumonia due to depletion of $\mathrm{CO}_{2}$ tissue reserves ${ }^{[30]}$. Meanwhile, other witnesses and the pathologist attributed the death to asphyxiation and/or hypoxia. Dr. Waters reported this speculation about hypoxia and asphyxiation, but did not elaborate on these alternatives to his hypothesis of $\mathrm{CO}_{2}$ toxicity.

Dr. Waters next cited the same anonymous source in this report of $\mathrm{CO}_{2}$ toxicity in an infant:

"Early this morning I was called to the ward to see a premature infant that was blue and hardly breathing in spite of a steady stream of carbon dioxide $5 \%$ and oxygen $95 \%$ or Carbogen. It gave occasional twitching gasps. This time I recognized carbon dioxide toxemia, so gave lots of pure oxygen at once, and the infant rapidly improved. After being given some saline subcutaneously and one-half hour of pure oxygen, it was crying lustily and in good condition. It seemed spectacular to the nurses how oxygen, not Carbogen, was effective."------- "In this hospital, I have been able to count fifty Carbogen cylinders and only two oxygen cylinders available for therapeutic purposes."

The assumption that $5 \%$ Carbogen toxicity caused these symptoms is far-fetched. $5 \%$ Carbogen is a stable mixture of $95 \%$ oxygen and $5 \% \mathrm{CO}_{2}$ prepared and stored at pressures below 750 torr, so that both gases remain in gaseous state, and there is no experimental evidence that $5 \% \mathrm{CO}_{2}$ causes any harmful effects. More likely an inexperienced nurse mistakenly substituted a tank of medical grade carbon dioxide in place of Carbogen. Medical grade $\mathrm{CO}_{2}$ is typically delivered in tanks pressurized above 760 torr so as to maintain the $\mathrm{CO}_{2}$ in liquid state and optimize tank storage capacity. $\mathrm{CO}_{2}$ released from such a tank readily forms a cool, odorless, invisible cloud that is temporarily affected by gravity, and fills dependent spaces. This would explain how $\mathrm{CO}_{2}$ filled the baby's bassinet and caused near-fatal asphyxiation ${ }^{\mathrm{DD}}$.

\section{Dr. Waters' commentary was as follows:}

"If this man's experience was an isolated instance, it would be of little significance. On the contrary, his letter is one of many received in my office describing fatal and non-fatal cases of carbon dioxide poisoning. It is my belief that atmospheres containing excess carbon dioxide are frequently toxic and often fatal to certain individuals. If illness has interfered with normal metabolism, or if the transport of this waste product from the cells of the body to the environmental atmosphere is handicapped by biochemical abnormality, by respiratory or cardiac deficiency, or by drug effect, any increase in the tension of carbon dioxide in the atmosphere inspired may prove detrimental."

Given the historical significance of these anonymous reports, this author dispatched inquiries to the Wood Library, UC San Francisco, and the University of Wisconsin, all of which maintain archives of Waters correspondence. None of them possessed copies of these anonymous letters. This seems strange given that Dr. Waters otherwise preserved his correspondence for posterity.

After citing his earlier report of $\mathrm{CO}_{2}$ anesthesia in dogs as proof of the narcotic properties of $\mathrm{CO}_{2}{ }^{[12]}$, Dr. Waters casually mentioned his subsequent endeavor to anesthetize humans using $\mathrm{CO}_{2}$ :

bon dioxide. The early practitioners knew that $\mathrm{CO} 2$ was dangerous in excessive concentrations, but they had no means to measure and monitor the gas. DDhttps://www.osha.gov/dts/hib/hib data/hib19960605.html 
"We then attempted to administer 30 percent in oxygen as an anesthetic agent to three apparently normal women, with the following result. The first was satisfactorily anesthetized for thirteen minutes with no untoward result during inhalation. The second had a convulsion on the operating table, during which the ward nurse appeared in the doorway to ask, "Doctor, what shall I do? The first patient is in a convulsion." The third patient tolerated ten minutes of carbon dioxide anesthesia, which was then changed to nitrous oxide. That evening, none of the three appeared to be worse for the experience."

It is indeed fortunate that none of these patients suffered asphyxiation brain damage, but Dr. Waters never mentioned that possibility. Instead, he attributed the convulsions to $\mathrm{CO}_{2}$ toxicity. The experience may well explain why he came to believe that hyperventilation was essential to eliminate dangerous accumulations of $\mathrm{CO}_{2}$.

\section{The Fourth Paper: "Carbon Dioxide"}

In 1938 Dr. Waters published a paper entitled "Carbon Dioxide" in which he challenged the research of Yandell Henderson $^{[78]}$ :

Clinical misapprehensions regarding the physiology of carbon dioxide seem to have had their inception in the work of Yandell Henderson in the early years of the present century. Henderson deduced from his experiments that surgical shock results from low carbon dioxide in the blood and tissues; that low carbon dioxide in the blood and tissues is a usual accompaniment of anaesthesia; and that hyperventilation of the lungs by the use of carbon dioxide and oxygen mixtures should prevent post-operative pulmonary atelectasis. All three of these deductions are fallacious. I make this statement based upon my own personal experience in clinic and laboratory, verified amply by the experience and experiments of others. The belief that shock is entirely dependent on low carbon dioxide is disproved by the fact that Seevers has hyperventilated dogs for many hours, reducing the blood carbon dioxide to points below 15 volumes per cent, without extreme drops in blood pressure' and with no evidences of shock. Carbon dioxide added to the inspired air of both men and animals whose blood pressures were low as a result of profound spinal anaesthesia has, in certain cases, resulted in a further drop of blood pressure, and has never resulted in a more sustained rise in blood pressure than could be produced by ventilating the lungs with oxygen alone. Eastman and Kreiselman have recently made a cinematographic record showing that, in reestablishing respiration following oxygen crisis or a complete apnoea due to oxygen want, carbon dioxide added to the oxygen used in artificial respiration has, on certain occasions, caused a further drop in blood pressure and always a less satisfactory circulatory recovery than was secured by artificial respiration with oxygen alone. Henderson's assumption that anaesthesia is accompanied by low carbon dioxide in alveoli, blood and tissues may have had a basis during the last century. Such is far from the case in anaesthesia of the present day.

\section{Dr. Waters also stated:}

"First of all, we must not lose sight of the fact that it $\left(\mathrm{CO}_{2}\right)$ is a waste product of body metabolism, just as are the constituents of urine. Reduction in the physiological efficiency of respiration tends to dam back carbon dioxide in the tissues just as physiological disturbances of the kidney tend to dam back the excretory products usually eliminated through that organ".

This assault on Dr. Henderson's research is unsubstantiated and unprofessional. Dr. Henderson's international fame was founded on an extensive body of careful, published, and scrutinized experiments that have stood the test of time. By comparison, Dr. Waters' research experience was negligible, and its shortcomings have been noted. His claim of "personal experience in clinic and laboratory, verified amply by the experience and experience of others" is unverifiable. The research of Seevers, Eastman, and Kreiselman is improperly cited. His claim that blood pressure is little changed by prolonged hyperventilation proves nothing in the absence of details. The effects of hyperventilation are complex and contextual; prolonged hyperventilation does not necessarily affect blood pressure; and declines in blood pressure due to combinations of spinal anesthesia and $\mathrm{CO}_{2}$ exposure are readily explained by harmless, synergistic reductions in microvascular flow resistance and blood viscosity ${ }^{[26,34,79]}$. Moreover, blood pressure is not a reliable standard of cardiovascular performance. Reductions in blood pressure are normally accompanied by beneficial improvements in tissue perfusion and oxygenation, as in trained athletes, while tachycardia and hypertension typically reflect harmful reductions in cardiac efficiency, tissue perfusion, and tissue oxygenation. Lastly, the persistent characterization of carbon dioxide as a "toxic waste product, like urine" suggests questionable motives.

Two years later, in 1940, Dr. Henderson published a scholarly summary of the studies that founded his viewpoint. Henderson's paper used the identical title of "Carbon Dioxide"EE . Although he did not dignify Dr. Water's attacks with a direct response, he undoubtedly had them in mind when he included this passage:

"The human mind is inherently inclined to take moralistic view of nature. Prior to the modern scientific era, which only goes back a generation or two, if indeed it can be said as yet even to have begun in popular thought, nearly every problem was viewed as an alternative between good and evil, righteousness and sin, God and the Devil. This superstitious slant still distorts the conceptions of health and disease; indeed, it is mainly derived from the experience of physical suffering. Lavoisier contributed unintentionally to this conception when he defined the life supporting character of oxygen and the suffocating power of carbon dioxide. Accordingly, for more than a century after his death, and even now in the field of respiration and related functions, oxygen typifies the Good and carbon dioxide is still regarded as a spirit of Evil. There could scarcely be a greater misconception of the true biological relations of these gases."

History has declared the winner of this contest between a medical physician and a $\mathrm{PhD}$ researcher. While the $\mathrm{CO}_{2}$ controversy raged, Dr. Waters successfully campaigned to create board certification that established anesthesiology as an independent specialty. He was determined that his graduates would pursue academic careers rather than enter private practice:

"My ambition is for the men who spend some time with me here to get eventually in teaching positions in other universities because I think that that is the only way we can hope to improve the specialty in the future. It has therefore been a dis-

EEhttp://www.members.westnet.com.au/pkolb/henders.htm 
appointment to me each time that one of my boys has gone to private practice." $\mathrm{FF}$

Dr. Waters indoctrinated the first generation of anesthesiology residents with his ideas and methods, and guided them to prestigious board certification and academic careers. These called themselves "Aqualumni". Of the original 60 trainees at Wisconsin, 40 occupied teaching positions in academic centers for a major portion of their careers, and half of them became chairpersons or directors of academic programs in medical schools of the United States and elsewhere. The Aqualumni were a cohesive group, remarkably loyal to the Chief. They faithfully attended yearly meetings in Madison, where they refreshed their relationships with one another and Dr. Waters. Even today thousands of practicing anesthesiologists can claim linkage to the and teachers' teachers ${ }^{\mathrm{GG}}$.

\section{The Waters Technique}

Dr. Waters introduced a practical technique of general anesthesia that addressed the shortcomings of the Crile/Henderson technique. The Waters technique utilized intravenous barbiturate induction, curare paralysis, and elective intubation that is faster and more pleasant than mask induction. Paralysis enabled elective intubation, prevented muscle tension and untoward movements, and optimized surgical convenience. Intubation accommodated additional surgical procedures, and eliminated laagent overpressure replaced morphine analgesia to control intra operative hypertension. Mechanical hyperventilation was introduced to eliminate the $\mathrm{CO}_{2}$ toxicity problem, optimize oxygenation, and minimize the work of breathing ${ }^{[33]}$. The Aqua-Alumni quickly promoted the Waters technique, and to this day it provides the foundation for general anesthesia throughout the world. Having accomplished his purpose, Dr. Waters retired to Florida in 1948, age 65, and thereafter inexplicably shunned his chosen specialty for 30 years until his death in 1979 at the age of 96.

Early Controversy: Despite its practical advantages, the Waters technique engendered considerable controversy, and questions about its safety apparently motivated the 1954 report of Beecher et al that equated muscle relaxants, and by implication the Waters technique itself, with exaggerated morbidity and mortality ${ }^{[80,81] \mathrm{HH}}$ Meanwhile, the declining cost of medical gases enabled a new generation of open circuit anesthesia machines that abolished $\mathrm{CO}_{2}$ asphyxiation, and halothane eliminated explosions ${ }^{[82,83]}$. journal was devoted to a symposium entitled "Carbon Dioxide and Man" that consisted of some 17 authoritative papers that purported to review all pertinent properties of $\mathrm{CO}_{2}{ }^{[84]}$. These papers speciously promoted hyperventilation and discouraged hypercarbia. There was no mention of $\mathrm{CO}_{2}$ benefits, hyperventilation hazards, Crile, Henderson, Lundy, balanced anesthesia, or Anoci-Association. Thereafter, editors, researchers and practitioners alike have ignored the consequences of mechanical hyperventilation in published studies, to the point that all published anesthesia research since 1950 requires reappraisal. Meanwhile,

${ }^{\mathrm{FF}}$ Carbon Copy of a letter from Ralph Waters to Lincoln Sise, May 5, 1933 Ralph Waters Papers, University of Wisconsin-Madison Archives, Madison, WI. Ralph Waters professional lineage through their own teachers ryngospasm, aspiration, and airway obstruction. Toxic inhalation Then, the November-December 1960 issue of Anesthesiology

medical practitioners abandoned Carbogen for fear of $\mathrm{CO}_{2}$ toxicity, while animal researchers embraced $\mathrm{CO}_{2}$ as a convenient means to anesthetize as well as euthanize animals ${ }^{[85,86]}$.

Research Influence of the Waters Technique: Animal studies performed at UC San Francisco exemplify the lingering influence of the Waters technique on anesthesia research. The 1967 report of Eisle, Eger, and Muallem entitled "Narcotic Properties of Carbon Dioxide in the Dog" began with this statement: "In 1820 the narcotic properties of $\mathrm{CO}_{2}$ were demonstrated by Hickman, and a century later anesthesia was produced in man with 30 per cent $\mathrm{CO}_{2}$ and $\mathrm{O}_{2}$." Both the title and the opening statement reflect the unfounded assumption by these researchers that the published studies of Hickman, Waters, and Leake had proved the anesthetic properties of $\mathrm{CO}_{2}$ beyond doubt ${ }^{[10]}$. Their stated objective was to clarify the relationship between $\mathrm{CO}_{2}$ anesthesia (aka narcosis) and acidosis. They anesthetized dogs with halothane and installed cannulas to sample arterial blood, venous blood and cerebrospinal fluid. Then they exposed the dogs to increasing concentrations of carbon dioxide while simultaneously decreasing the halothane concentration. They were able to eliminate the halothane altogether as $\mathrm{FICO}_{2}$ approached $30 \%$, at which point they observed reductions in nervous reflex activity equivalent to $1 \mathrm{MAC}$ halothane (i.e. the dogs did not move when subjected to painful surgical incision or tail clamping). Unsurprisingly, these effects, which were due to $\mathrm{CO}_{2}$ asphyxiation, were closely followed by seizures, deaths, and cerebrospinal fluid acidosis due to anaerobic cellular respiration in brain tissue. The acidosis appeared first in brain tissue, which has the highest oxygen requirements of all tissues, and thus appeared in CSF shortly before it appeared in arterial and venous blood.

Inexplicably, the researchers reported only $\mathrm{PaCO}_{2}$ and $\mathrm{pH}$ results, and omitted $\mathrm{pO}_{2}$ and $\mathrm{O}_{2}$ saturation data. Blood gas analysis directly measures arterial oxygen tension $\left(\mathrm{PaO}_{2}\right)$, carbon dioxide tension $\left(\mathrm{PaCO}_{2}\right)$, and acidity $(\mathrm{pH})$, from which oxygen saturation $\left(\mathrm{SaO}_{2}\right)$ can be derived. ${ }^{\text {IITherefore the }} \mathrm{pO}_{2}$ and $\mathrm{SaO}_{2}$ data was unquestionably in their possession. Inexplicably, they also ignored the obvious presence of asphyxiation that caused hypoxia, anaerobic respiration, and lactic acidosis. The missing $\mathrm{pO}_{2}$ and/or $\mathrm{SaO}_{2}$ data would have settled the matter. When this author asked Dr. Eger via email if $\mathrm{CO}_{2}$ asphyxiation might explain these observations, he replied "I think not." When asked why $\mathrm{pO}_{2}$ data was excluded from the report, he stated that he "could not recall" the reason, but he insisted that his study reflected $\mathrm{CO}_{2}$ narcosis rather than asphyxiation. These facts suggest that the researchers were motivated by something other than science. Despite these defects, the study confirmed that potentially lethal asphyxiation occurs suddenly at $\mathrm{FICO}_{2} 30 \%$ despite $70 \%$ oxygen supplementation ${ }^{[34]}$.

In 2007, Dr. Eger et al produced a similar study entitled "Anesthetic Properties of Carbon Dioxide in the Rat"[11]. As before, this report opened by stating: "The anesthetic effects of $\mathrm{CO}_{2}$ have long been recognized" and cited Hickman's report as proof[87]. As in the previous study, asphyxiation explains the observed results, but asphyxiation was never mentioned. The study avoided the issue by neglecting oxygen saturation data that could have easily been obtained using pulse oximetry

\footnotetext{
${ }^{\mathrm{GG}}$ http://www.woodlibrarymuseum.org/library/pdf/W0071.pdf

${ }^{\mathrm{HH}}$ http://www.woodlibrarymuseum.org/library/pdf/W0071.pdf

"http://en.wikipedia.org/wiki/Arterial_blood_gas
} 
to confirm or refute the presence of asphyxiation. Both of these studies were published in prominent anesthesiology journals, and it seems noteworthy that the editors and reviewers of both journals failed to object to these egregious shortcomings.

\section{Paralysis Problems}

Residual paralysis has remained problematic since the introduction of the Waters technique ${ }^{[81] J J}$. Paralysis necessitates mechanical ventilation that readily damages lung tissues, depletes $\mathrm{CO}_{2}$ tissue reserves, undermines opioid clearance, exaggerates respiratory depression, nausea and vomiting, decreases cardiac efficiency, and reduces tissue perfusion and oxygenation in the brain, bowel, and other vital organs and tissues $^{[21,26,27,33,37,88-96]}$. Awareness during anesthesia is caused by a combination of paralysis, inadequate analgesia, and inadvertent exhaustion of inhalation agent in the vaporizer canister, so that the patient regains awareness during surgery and perceives intense surgical pain, but cannot move or otherwise alert the anesthetist to his plight ${ }^{\mathrm{KK}}$.

\section{Opioids and Hyperventilation}

Mechanical hyperventilation is incompatible with opioid treatment. It depletes $\mathrm{CO}_{2}$ tissue reserves, paralyzes respiratory chemoreceptors, impairs opioid clearance ${ }^{[37]}$, exaggerates opioid respiratory depression, and necessitates prolonged postoperative "weaning" after surgery ${ }^{[5]}$. Even when opioid dosage is carefully minimized, hyperventilation causes the occult "opioid hypersensitivity syndrome" that has claimed numerous victims ${ }^{[97] \mathrm{LL}}$. Hyperventilated patients appear to breathe normally during emergence, but their respiratory drive remains unstable until metabolic activity has restored $\mathrm{CO}_{2}$ tissue reserves and chemoreceptor function. During this vulnerable period, which may last hours, patients may stop breathing and die if they fall asleep for any reason ${ }^{[17,23,98]}$. Small doses of opioids and sedatives may unpredictably precipitate sleep and respiratory arrest, especially in elderly patients with low metabolic rates. Such disasters are typically attributed to the supposedly unpredictable effects of opioids, while the occult role of hyperventilation escapes notice because the victims appear to have completely recovered from anesthesia ${ }^{[3,4]}$. The resulting fear of opioids discourages their use, which indirectly exaggerates stress related postoperative problems including fever, tachycardia, hypertension, dysrhythmias, laryngospasm, dementia, bowel ileus, myocardial infarction, stroke, exaggerated pain, nausea, vomiting, atelectasis, systemic inflammation, Adult Respiratory Distress Syndrome (ARDS), Systemic Inflammatory Response Syndrome (SIRS) and death ${ }^{[46,99]}$. There are also substantial increases in cancer and heart disease in the distant aftermath of surgery ${ }^{[48]}$. All these problems are exaggerated in elderly patients, and all of them could be substantially mitigated by effective opioid supplementation, but opioids are incompatible with hyperventilation ${ }^{[5,17,18,38,43,44,100,101]}$. The exaggerated reliance on dangerous muscle relaxants and toxic inhalation agent overpressure engendered by the Waters technique further exaggerates morbidity and mortality ${ }^{[102-105]}$.

\section{Altered Beliefs, Habits, and Practices}

With the Crile/Henderson technique, practitioners rou-

${ }^{J}$ http://www.anesthesiologynews.com/ViewArticle.aspx?d=Clinical+Anesthesiology\&d_id=1\&i=July+2012\&i_id=864\&a_id=21217 tinely utilized morphine to control surgical stress, so that mild hypotension was regarded as a beneficial manifestation of effective surgical stress control, and tachycardia and hypertension were attributed to inadequate analgesia. They used $\mathrm{CO}_{2}$ supplementation to offset the respiratory depressant effects of morphine and to optimize cardiorespiratory function and morphine dosage, so that they regarded mild respiratory acidosis as beneficial and alkalosis as harmful.

With the Waters technique mechanical hyperventilation was assumed to be essential to eliminate the supposedly toxic and narcotic effects of $\mathrm{CO}_{2}$. Morphine was replaced by toxic inhalation agent overpressure, which was incorrectly assumed to have analgesic properties. Thus respiratory alkalosis came to be regarded as beneficial, and respiratory acidosis as harmful. Hypertension came to be regarded as a manifestation of cardiac reserve, and hypotension came to be regarded as evidence of impending disaster. Opioids came to be regarded as unpredictable and dangerous, because hyperventilation is incompatible with opioids. Intravenous muscle relaxants and hypnotic agents came to be regarded as essential to prevent dental and vocal cord damage and facilitate intubation during induction, even though mask induction was routine practice before IV access became available, and remains arguably safer ${ }^{[106,107]}$.

\section{Anesthesia Theory}

The Waters technique has also disrupted anesthesia theory development, because it assumes that the brain modulates all forms of surgical stress, so that inhalation agents theoretically eliminate surgical stress simply by inhibiting consciousness. Thus most efforts to develop anesthesia theory focus on the effects of inhalation agents on the brain and ignore spinal cord nervous pathways that bypass the brain and communicate directly with SNS ganglia in the chest and abdomen, and are little affected by anesthetic agents ${ }^{[108]}$. Conventional theory also overlooks the independent effects of tissue disruption, which releases tissue factor into systemic circulation ${ }^{[2,109,110]}$.

Carbogen: Carbogen is a mixture of carbon dioxide and oxygen, typically $5 \% \mathrm{CO}_{2}$ mixed with $95 \% \mathrm{O}_{2}$, that can be conveniently used to enhance tissue oxygenation in a wide variety of medical conditions. Yandell Henderson's research inspired its installation on fire trucks in New York, Chicago, and other major cities, and physicians as well as firemen used it to treat myocardial infarction, stroke, pneumonia, asthma, newborn babies, drowning victims, carbon monoxide poisoning and other mala$\operatorname{dies}^{[14]}$. It was credited with saving many lives, but it was quickly abandoned and forgotten after Dr. Waters publicized the purported toxicity of carbon dioxide. The abandonment of Carbogen is especially unfortunate considering that modern research has demonstrated that inhaling small concentrations of $\mathrm{CO}_{2}$ increases microvascular perfusion via a mechanism that involves nitric oxide $^{[34,111,112]}$. This explains why inhaling $\mathrm{CO}_{2}$ reduces blood viscosity and enhances cardiac output, cardiac efficiency, tissue perfusion, tissue oxygenation, and respiratory drive $\mathrm{e}^{[35,40]}$. $\mathrm{CO}_{2}$ also offsets the respiratory depression of opioids. If all this were properly understood, Carbogen therapy could be restored as a useful, effective, inexpensive, and convenient treatment for

${ }^{\text {KK }}$ Anesthesiology News ISSUE: JANUARY 2015 | VOLUME: 41:1

LLhttp://www.apsf.org/newsletters/html/2010/winter/11_opioids.htm 
acute myocardial infarction, stroke, and perioperative problems.

\section{The Rediscovery of Crile}

Solid science cannot be forgotten forever. In 1959 De Castro described neuroleptanalgesia ${ }^{[113,114]}$, and in 1969 Lowenstein demonstrated that morphine supplementation optimizes cardiac bypass outcome ${ }^{[115]}$. Anesthesiologists quickly embraced the high potency, low toxicity, and short half-life of a new generation of synthetic opioids introduced by the Janssen Corporation as a means to optimize surgical outcome ${ }^{[23,43,44,116]}$. Unfortunately, the incompatibility of opioids and hyperventilation remained unappreciated, and even synthetic opioids necessitated prolonged, treacherous, impractical and expensive postoperative "weaning" to restore $\mathrm{CO}_{2}$ tissue reserves and reliable respiratory drive.

\section{The Rediscovery of Henderson}

In the late 1980's Critical care specialists inadvertently re-discovered $\mathrm{CO}_{2}$ supplementation while searching for better ways to manage ARDS ${ }^{[33]}$. They called it "permissive hypercarbia" and embraced it as a means to optimize outcome in ICU patients. Both anesthesia and critical care clinical research soon confirmed its merits ${ }^{[117,118]}$. Permissive hypercarbia is now routinely employed in the care of ICU patients to optimize cardiac output, minimize lung damage, and optimize respiratory drive. Strangely, little or no discussion of the therapeutic benefits of permissive hypercarbia have appeared in anesthesia publications, regardless of the rich anesthesia history of $\mathrm{CO}_{2}$ supplementation and the availability of capnography.

\section{Recent History}

Sudden changes have buffeted anesthesia practice in recent years. Capnography was introduced to operating rooms in North America around 1990, even as critical care specialists embraced permissive hypercarbia and armies of respiratory therapists became necessary to manage postoperative weaning necessitated by counterproductive combinations of opioids and hyperventilation during surgery. If capnography had been introduced only a few years earlier, during the heyday of opioid stress research, the complimentary relationship between opioids and hypercarbia might have been re-discovered ${ }^{[18,98,119]}$. Instead, even as Crile and Henderson enjoyed posthumous, anonymous vindication, the fickle finger of fate blindsided anesthesia progress from two directions at once. Firstly, insurance companies altered reimbursements to eliminate the expensive postoperative weaning necessitated by incompatible combinations of opioids and hyperventilation ${ }^{[120]}$. Secondly, capnography and pulse oximetry largely abolished airway disasters, causing malpractice insurance rates to plummet, which fostered the fiction that further improvements in anesthesia safety were impossible ${ }^{[121]}$. As a consequence, outpatient surgery centers proliferated; Crile's principles of early admission, premedication, late discharge, and analgesic supplementation were abandoned; and anesthesiologists ignored permissive hypercarbia, re-abandoned opioids, and re-embraced the classic Waters technique ${ }^{[122]}$. By 1997 the results of inadequate surgical stress control manifested as the previously unknown Systemic Inflammatory Response Syndrome
("SIRS"), but the compelling coincidence was ignored ${ }^{[46,123-125]}$. The tragedy became complete in 2005, when Dr. Terri Monk published her landmark study that unexpectedly revealed a $30 \%$ increase in morbidity and mortality in the distant aftermath of surgery that is influenced by anesthetic management ${ }^{[48]}$. This should have inspired fresh interest in balanced anesthesia. Instead, Dr. Monk was pressured into silence; the distant morbidity and mortality following surgery was ignored; anesthesia literature suddenly began to decry the dangers of opioids; prominent professors promoted the preposterous premise that opioids cause cancer $^{[126,127]}$; and new regulations restricted clinical research to the purview of powerful pharmaceutical companies. By 2010, it became evident that numerous healthy geriatric patients die mysteriously of unexplained respiratory arrest within hours after uneventful surgery and within minutes after treatment with small doses of opioids and sedatives ${ }^{[07] \mathrm{MM} N \mathrm{~N}}$. This should have focused attention on the harmful effects of hyperventilation and the need for guidelines and standards for $\mathrm{CO}_{2}$ management, but instead the problem was dismissed as "opioid hypersensitivity", and the issue vanished ${ }^{\mathrm{OO}}$.

\section{Airway Management}

Dr. Waters founded the anesthesiology profession on the principle of secure airway, but that valuable principle is being abandoned as anesthesiologists increasingly embrace inherently hazardous "open airway" techniques. These eliminate problematic muscle relaxants but they paralyze the ability of capnography to measure $\mathrm{FICO}_{2}$ and they invite fire, aspiration, airway obstruction, and occult hypoventilation ${ }^{\mathrm{PP}}$. In large measure, these alterations in anesthesia practice reflect reimbursement alterations that require rapid turnover and discharge regardless of safety. Opioid supplementation to reduce morbidity and mortality has likewise fallen victim to such considerations. Also forgotten is the superior safety of mask induction. Sevoflurane has revolutionized its utility, and it deserves a fresh look ${ }^{[107]}$. Many practitioners presume that intravenous hypnosis and paralysis are essential to enable intubation, prevent dental and vocal cord damage, and assure patient comfort, but these assumptions lack substantiation ${ }^{[106]}$. Combinations of surprise and paralysis invariably accompany induction airway disasters, and residual paralysis persistently plagues anesthesia practice $^{[81]}$. Fatigue, hunger and hubris readily frustrate the ability of pre-operative evaluation and awake intubation to prevent airway disasters ${ }^{[128,129] \mathrm{QQ}}$. Routine mask induction and intubation without paralysis enables safe retreat from unexpected airway difficulties by ventilating with pure oxygen, and thereby offers the means to avoid airway disasters. It eliminates irreversible paralysis of airway muscles that can unexpectedly obstruct the airway, causing "can't intubate, can't ventilate" predicaments. Mask induction also eliminates bolus intravenous agent toxicity, and incorporates pre-oxygenation and de-nitrogenation. Modern monitors, advanced inhalation agents, synthetic opioids and $\mathrm{CO}_{2}$ supplementation enable efficient mask induction, intubation, maintenance, and emergence with little or no need for hazardous muscle relaxants ${ }^{[106,107,130]}$.

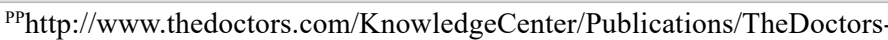
Advocate/CON_ID_003920

QQhttp://www.thedoctors.com/KnowledgeCenter/PatientSafety/articles/ CON_ID_001632
} 


\section{Which Fork in the Yellow Brick Road of Progress?}

Regardless of these discouraging trends, the future of anesthesia is pregnant with potential. Early anesthetists lacked modern monitors, machines, drugs and equipment, but they possessed superior science. It is now clear that mild hypercarbia is benign and beneficial; hypocarbia is harmful; inhalation agents are toxic and devoid of analgesic properties; muscle relaxants are hazardous; and opioid analgesia added to general anesthesia improves surgical outcome ${ }^{[2,131]}$. Anesthetic agents and equipment have improved since the era of Crile and Henderson. Synthetic opioids are nearly devoid of toxicity. New inhalation agents offer superior blood/gas solubility, reduced toxicity, and less offensive smell. The dangers of agent explosion and $\mathrm{CO}_{2}$ asphyxiation are long gone. Soda lime no longer serves any purpose ${ }^{[86,132-136]}$. Pulse oximetry continuously warns of occult hypoxia. Capnography has revolutionized airway management, but its ability to continuously monitor and measure $\mathrm{FICO}_{2}$, enhance opioid dosage, and optimize surgical safety and patient comfort remains unappreciated. The anesthesiology profession is poised at the threshold of revolutionary advance if the full potential of modern machines, monitors, agents, and research information is appreciated.

\section{Anesthesia and Stress Theory}

Anesthesia is surgical stress control. Its purpose is to prevent the pathological stress reaction that occurs in the aftermath of surgical tissue disruption. The ultimate objective of anesthesia research is a theory that enables the alteration of anesthetic technique to minimize surgical stress and optimize surgical outcome.

Prior to the discovery of anesthesia, invasive surgery was generally avoided, because most patients died in agony within hours regardless of surgical success. The discovery of anesthesia provided the practical means to reversibly ablate consciousness, which reduced surgical stress to the point that most patients survive, and thereby revolutionized surgery. Nevertheless, the surgical stress syndrome remains problematic in the form of fever, tachycardia, hypertension, bowel ileus, exaggerated pain, allodynia, dementia, acute renal failure, myocardial infarction, pulmonary embolus, stroke, and death. Additional morbidity and mortality follows in the distant aftermath of surgery in the form of cancer, heart disease, and chronic illness.

The habit of hyperventilation has derailed anesthesia theory development for more than 70 years, but the recent discovery and description of Selye's mammalian stress mechanism confers a fresh theory of anesthesia that corroborates, clarifies, and extends Crile's observations ${ }^{[2,131,137]}$. Surgical stress activates Selye's mechanism via three pathways that synergistically activate coagulation Factors VII and VIII, causing the surgical stress syndrome:

1. Nociception activates sympathetic ganglia via spinal cord pathways, which activates Factor VIII. Effective analgesia must be maintained throughout surgery to control nociception and optimize outcome, but analgesia has limited effect on consciousness.

2. Consciousness interprets nociception as pain and integrates all forms of sensory input, assesses risk and danger, and pre-emptively activates the sympathetic nervous system via hypotha- lamic pathways that activate Factor VIII. Anesthesia inhibits consciousness, but has little effect on nociception. Effective anesthesia must be maintained throughout surgery to optimize outcome.

3. Tissue disruption releases tissue factor into systemic circulation and activates Factor VII ${ }^{[10]}$. At present there is nopractical means to inhibit tissue factor.

Stress theory indicates that synergistic combinations of anesthesia and analgesia, applied continuously throughout surgery, can minimize the manifestations of the surgical stress syndrome and reduce the immediate and distant morbidity and mortality of surgery by $30 \%$ or more ${ }^{[43,44,48,100,138]}$. It further implies that the administration of an effective antidote for tissue factor at the conclusion of surgery, after effective coagulation is assured, would prevent positive feedback in the stress mechanism and abolish the surgical stress syndrome altogether. Such theory and treatments would revolutionize medicine in general as well as surgery ${ }^{[10]}$.

\section{A Practical Technique to Optimize Surgical Stress Control}

Risk free anesthesia has yet to be invented, but stress theory can be utilized to alter anesthetic technique to optimize surgical outcome using presently available medications, and equipment. The limited clinical experience of this author indicates that elective mask induction and intubation followed by maintenance of general endotracheal anesthesia with $1 / 2$ MAC anesthetic agent complemented by judicious opioid analgesia, minimal paralysis, and permissive hypercarbia combines the advantages of the Waters technique with those of the Crile/ Henderson technique, and eliminates the shortcomings of both $^{[104,105,107,130,139,140]}$. It offers a practical, universally applicable means to minimize toxicity and optimize safety, simplicity, efficiency, cost, predictability, patient comfort, and outcome using presently available machines, monitors, and agents. Safe and beneficial hypercarbia is achieved with $\mathrm{FICO}_{2} 10 \%$ or less, which is the upper limit enabled by modern anesthesia machines $^{[34,36,117,141,142]}$. The technique is pleasant for patients, safer than open airway techniques, and equally efficient. It is safer, simpler, faster, and less problematic than block techniques, and it enables equivalent control of pain and stress. It minimizes morbidity and mortality during and immediately after surgery and there is every reason to believe that it can reduce cancer and heart disease by $30 \%$ or more in the distant aftermath of surgery ${ }^{[43,44,48,100,116,138]}$.

\section{The Legacy of Dr. Ralph Waters}

Dr. Ralph Waters is presently venerated as the political genius who founded the anesthesiology profession ${ }^{\mathrm{RR}}$, but history may prove less generous. His attacks on Dr. Henderson were unjustified. He founded the anesthesiology profession on faulty science that has directly and indirectly abolished the therapeutic benefits of carbon dioxide, discouraged opioid treatment, exaggerated surgical morbidity and mortality, undermined patient comfort, derailed medical research, undermined professional progress, established inhumane $\mathrm{CO}_{2}$ asphyxiation as a standard tool of animal research ${ }^{[85,86]}$, and now threatens the very existence of the anesthesiology profession, because anesthesiologists can no longer claim to provide superior service. Regret-

${ }^{R R}$ http://www.woodlibrarymuseum.org/library/pdf/W0071.pdf 
tably, he is no longer available to explain his motives. These cannot be dismissed as confusion, because the consequences of hyperventilation and asphyxiation were well understood in his time ${ }^{[14]}$. He surely realized that eliminating $\mathrm{CO}_{2}$ supplementation would exaggerate the risk of ether and cyclopropane explosions that menaced patients and personnel alike. Thus his only apparent motive was to promote specialty status for MD anesthesia, regardless of consequences.

\section{Conclusion}

Power, politics and privilege perpetually prevail over all forms of human endeavor. Nevertheless it is sobering to observe how politics enabled a single individual to cause so much harm to so many for so long; how easily medical principles were distorted; and how powerful corporations promote profits at the expense of public health. The minor minions of Mammon go to prison, but those who pay them and those who publish them remain unscathed ${ }^{\text {SSTTUUVVWw }}$.

The purpose of any medical profession is to provide the best medical care that science can offer, but the anesthesiology profession has ignored the proven benefits of opioid analgesia and $\mathrm{CO}_{2}$ supplementation, and the consequences of inadequate analgesia and hyperventilation, for more than 60 years. The failure to implement standards and guidelines for $\mathrm{CO}_{2}$ management reflects deep-seated defects in beliefs, habits, practices, education, and professional leadership that must be corrected. Hyperventilation is not an "option". $\mathrm{CO}_{2}$ depletion is inherently dangerous, confers no benefits, and should be condemned as malpractice. The lingering tolerance of the mythical notions of $\mathrm{CO}_{2}$ toxicity and narcosis is inexcusable ${ }^{[10,11,84]}$.

The abandoned principles and practices of the previous generation merit reappraisal. With capnography, pulse oximetry, modern anesthesia machines, synthetic opioids and improved inhalation agents it is now practical and safe to combine the advantages of the Waters technique with those of the Crile/Henderson technique, and eliminate the shortcomings of both. Such professional advance can substantially reduce morbidity and mortality, minimize costs, improve efficiency, optimize patient comfort, restore anesthesia advance, pave the path for effective pharmaceutical development, and promote additional medical progress. Such advance is inevitable, if only because science cannot be denied forever. It also promises priceless prestige for the profession.

Reform won't be easy. Inspired leadership is lacking, and the hour is late. However, there is enormous opportunity. This author believes that the complexity of anesthesia practice merits superior medical education and training, and that the anesthesiology profession merits preservation. Must progress await our great-grandchildren? Why not us? Why not now?

"Every violation of truth is not only a sort of suicide in the liar, but is a stab at the health of human society."---Ralph Waldo Emerson

"It must be considered that there is nothing more difficult to carry out nor more doubtful of success nor more dangerous to handle than to initiate a new order of things; for the reformer has enemies in all those who profit by the old order, and only lukewarm defenders in all those who would profit by the new order; this lukewarmness arising partly from the incredulity of mankind who does not truly believe in anything new until they actually have experience of it." ---Machiavelli

\section{References}

1. Merchant, R.N. Special announcement: Guidelines to the practice of anesthesia--revised edition 2015. (2015) Can J Anaesth 62(1): 8-9.

2. Coleman, L.S. 30 Years Lost in Anesthesia Theory. (2012) Cardiovasc Hematol Agents Med Chem 10(1): 31-49.

3. Coleman, L.S. A call for standards on perioperative $\mathrm{CO}(2)$ regulation. (2011) Can J Anaesth 58(5): 473-474.

4. Coleman, L.S. Intraoperative Hyperventilation May Contribute to Postop Opioid Hypersensitivity. (2010) apsf Newsletter.

5. Bellville, J.W. The Effect of Drugs on the Respiratory Response to CarbonDioxide. (1960) Anesthesiology 21: 727-741.

6. Foregger, R. John Snow's Early Research on Carbon Dioxide. (1960) Anesthesiology 21: 20-25.

7. Henderson, Y. Carbon Dioxide. (1940) Cyclopedia of Medicine. 8. Waters, R.M. Carbon Dioxide: Its Place in Anaesthesia. (1927) Can Med Assoc J 17(12): 1510-1513.

9. Waters, R.M. Toxic Effects of Carbon Dioxide. (1933) JAMA 519: 219-224.

10. Eisele, J.H., Eger, E.I., $2^{\text {nd }}$, Muallem M. Narcotic properties of carbon dioxide in the dog. (1967) Anesthesiology 28(5): 856-865.

11. Brosnan, R.J., Eger, E.I., 2 ${ }^{\text {nd }}$, Laster, M.J., et al. Anesthetic properties of carbon dioxide in the rat. (2007) Anesth Analg 105(1): 103-106. 12. Leake, C.D.W, R.M. The Anesthetic Properties of CarbonDioxide. (1928) J Pharmacol Exp Ther 33.

13. Badino, G. The legend of carbon dioxide heaviness. (2009) Journal of Cave and Karst Studies 71(1): 100-107.

14. Campbell, A., Poulton, E.P. Oxygen and carbon dioxide therapy. (1934) London Oxford University Press, H. Milford.

15. Nichols-George, Jr. Serial changes in tissue carbon dioxide content during acute respiratory acidosis. (1958) J Clin Invest 37(8): 1111-1122. 16. Prabhakar, N.R. O2 sensing at the mammalian carotid body: why multiple O2 sensors and multiple transmitters? (2006) Exp Physiol 91(1): 17-23.

17. Fink, B.R. Influence of cerebral activity in wakefulness on regulation of breathing. (1961) J Appl Physiol 16: 15-20.

18. Bellville, J.W., Howland, W.S., Seed, J.C., et al. The effect of sleep on the respiratory response to carbon dioxide. (1959) Anesthesiology 20: 628-634.

19. Lahiri, S., Roy, A., Baby, S.M., et al. Oxygen sensing in the body. (2006) Prog Biophys Mol Biol 91(3): 249-286.

20. Lahiri, S., DeLaney, R.G. Stimulus interaction in the responses of carotid body chemoreceptor single afferent fibers. (1975) Respir physiol 24(3): 249-266.

21. Corne, S., Webster, K., Younes, M. Hypoxic respiratory response during acute stable hypocapnia. (2003) Am J Respir Crit Care Med 167(9): 1193-1199.

22. Ong, B.Y., Cohen, M.M., Palahniuk, R.J. Anesthesia for cesarean section--effects on neonates. (1989) Anesth Analg 68(3): 270-275.

23. Stanley, T.H., Egan, T.D., Van-Aken, H. A tribute to Dr. Paul A. J. Janssen: entrepreneur traordinaire, innovative scientist, and significant contributor to anesthesiology. (2008) Anesth Analg 106(2): 451-462.

24. Hanawald, J. Rapid Gas Change During ECMO Linked to Mortality Risk. (2011) Anesthesiology News 37: 8.

25. Hanawald, J. Rapid Gas Change During ECMO Linked to Mortality
${ }^{\mathrm{sS}} \mathrm{http} / / /$ en.wikipedia.org/wiki/Yoshitaka_Fujii

TThttp://www.anesthesiologynews.com/ViewArticle.aspx?d=Web\%2bExclusives\&d_id=175\&i=October+2010\&i_id=669\&a_id=16095

uUhttp://en.wikipedia.org/wiki/Scott Reuben

www.ommegaonline.org
${ }^{\mathrm{v}} \mathrm{http} / / /$ www.truth-out.org/news/item/9049-why-are-these-fraudulent-papers-not-retracted

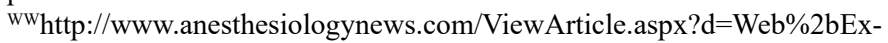
clusives\&d id $=175 \& \mathrm{i}=$ October $+2010 \& \mathrm{i}$ id $=669 \& \mathrm{a}$ id $=16095$

J Anesth Surg | volume 3: issue 1 
Risk. (2012) Anesthesiology News 37: 8.

26. Albrecht, R.F., Miletich, D.J., Ruttle, M. Cerebral effects of extended hyperventilation in unanesthetized goats. (1987) Stroke 18(3): 649655.

27. Marion, D.W., Firlik, A., McLaughlin, M.R. Hyperventilation therapy for severe traumatic brain injury. (1995) New Horiz 3(3): 439-447. 28. Brown, E. Physiological effects of high concentrations of ca. (1930) United States naval medical bulletin.

29. Mannucci, P.M., Ruggeri, Z.M., Gagnatelli, G. Nervous regulation of factor-VIII levels in man. (1971) Br J Haematol 20(2): 195-207. 30. Henderson, Y. A Lecture ON RESPIRATION IN ANAESTHESIA: CONTROL BY CARBON DIOXIDE. (1925) Br Med J 2(3390): 11701175 .

31. Riegels, N., Richards, M.J. Humphry Davy: his life, works, and contribution to anesthesiology. (2011) Anesthesiology 114(6): 12821288.

32. Reivich, M. Arterial Pco2 and Cerebral Hemodynamics. (1964) Am J Physiol 206: 25-35.

33. Kavanagh, B. Normocapnia vs hypercapnia. (2002) Minerva Anestesiol 68(5): 346-350.

34. Komori, M., Takada, K., Tomizawa, Y., et al. Permissive range of hypercapnia for improved peripheral microcirculation and cardiac output in rabbits. (2007) Crit Care Med 35(9): 2171-2175.

35 . Akca, O. Optimizing the intraoperative management of carbon dioxide concentration. (2006) Curr Opin Anaesthesiol 19(1): 19-25.

36. Akca, O. Hypercapnia: what is the upper limit? (2005) Paediatr anaesth 15(1): 80-81.

37. Ainslie, S.G., Eisele, J.H. Jr., Corkill, G. Fentanyl concentrations in brain and serum during respiratory acid--base changes in the dog. (1979) Anesthesiology 51(4): 293-297.

38. Bellville, J.W., Escarraga, L.A., Wallenstein, S.L., et al. Relative respiratory depresant effects of oxymorphone (numorphan) and morphine. (1960) Anesthesiology 21: 397-400.

39. Akca, O., Liem, E., Suleman, M.I., et al. Effect of intra-operative end-tidal carbon dioxide partial pressure on tissue oxygenation. (2003) Anaesthesia 58(6): 536-542.

40. Akca, O., Doufas, A.G., Morioka, N., et al. Hypercapnia improves tissue oxygenation. (2002) Anesthesiology 97(4): 801-806.

41. Akca, O., Sessler, D.I., Delong, D., et al. Tissue oxygenation response to mild hypercapnia during cardiopulmonary bypass with constant pump output. (2006) Br J Anaesth 96(6): 708-714.

42. Akca, O. Carbon dioxide and tissue oxygenation: is there sufficient evidence to support application of hypercapnia for hemodynamic stability and better tissue perfusion in sepsis? (2008) Intensive Care Med 34(10): 1752-1754.

43. Myles, P.S., Hunt, J.O., Fletcher, H., et al. Remifentanil, fentanyl, and cardiac surgery: a double-blinded, randomized, controlled trial of costs and outcomes. (2002) Anesth Analg 95: 805-812.

44. Mangano, D.T., Siliciano, D., Hollenberg, M., et al. Postoperative myocardial ischemia. Therapeutic trials using intensive analgesia following surgery. The Study of Perioperative Ischemia (SPI) Research Group. (1992) Anesthesiology 76(3): 342-353.

45. Crile, G.W., lower, G.W. Anoci-association. (1914) Philadelphia: Saunders.

46. Adembri, C., Kastamoniti, E., Bertolozzi, I., et al. Pulmonary injury follows systemic inflammatory reaction in infrarenal aortic surgery. (2004) Crit Care Med 32(5): 1170-1177.

47. Modesti, P.A., Gamberi, T., Bazzini, C., et al. Response of Serum Proteome in Patients Undergoing Infrarenal Aortic Aneurysm Repair. (2009) Anesthesiology 111(4): 844-854.

48. Monk, T.G., Saini, V., Weldon, B.C., et al. Anesthetic management and one-year mortality after noncardiac surgery. (2005) Anesth Analg 100(1): 4-10.

49. Cartwright, P., Prys-Roberts, C., Gill, K., et al. Ventilatory depression related to plasma fentanyl concentrations during and after anesthesia in humans. (1983) Anesth Analg 62(11): 966-974.
50. Matteo, R.S., Ornstein, E., Schwartz, A.E., et al. Effects of hypocarbia on the pharmacodynamics of sufentanil in humans. (1992) Anesth Analg 75(2): 186-192.

51. Barry, J.M. The great influenza: the epic story of the deadliest plague in history. New York (2005) Penguin Books.

52. Crile, G.I. The Technique of Direct Transfusion of Blood. (1907) Ann Surg 46(3): 329-332.

53. Crile, G.W. The Most Important Factor in the Treatment of War Wounds and the Most Important Factor in Civilian Surgery-the Good Surgeon. (1919) Ann Surg 70(4): 385-387.

54. Crile, G.W. Notes on Military Surgery. (1915) Ann Surg 62(1): 1-10. 55. Crile, G.W. Treatment of Four Hundred and Twenty Infected Wounds under Battle Conditions arriving on the Average of Fifty-Eight and one-third Hours after Injury, without previous Surgical Treatment. (1918) Can Med Assoc J 8(11): 961-965.

56. Crile, G., Dolley, D.H. An Experimental Research into the Resuscitation of Dogs Killed by Anesthetics and Asphyxia. (1906) J exp med 8(6): 713-725.

57. Crile, G., Dolley, D.H. On the Effect of Complete Anemia of the Central Nervous System in Dogs Resuscitated after Relative Death. (1908) The J exp med 10(6): 782-810.

58. Crile, G.W. Influence of Inhalation Anaesthesia on the Acidity of the Blood as Determined by Estimation of H-Ion Concentration. (1915) Ann Surg 61(1): 6-9.

59. Crile, G.W. The Phenomena of Acidosis and Its Dominating Influence in Surgery. (1915) Ann Surg 62(3): 257-263.

60. Crile G. III. Psychical Aspects of Grave's Disease. (1908) Ann Surg 47(6): 864-869.

61. Crile, G.W. II. The Identity of Cause of Aseptic Wound Fever and So-called Post-Operative Hyperthyroidism and Their Prevention. (1913) Ann Surg 57(5): 648-652.

62. Henderson, Y. Public Service as an Element in the Life of the American Scientist. (1933) Science 77(2007): 584-585.

63. Henderson, Y. Automobile Exhaust Gas as a Health Hazard. (1922) Trans Am Climatol Clin Assoc 38: 14-19.

64. Henderson, Y. Physiological Observations on Pike's Peak, Colorado, made in the summer of 1911. (1912) Trans Am Climatol Assoc 28: 11-15.

65. Henderson, Y. Resuscitation with Carbon Dioxide. (1936) Science 83(2157): 399-402.

66. Henderson, Y. The Wesley M. Carpenter Lecture: Atelectasis, Massive Collapse and Related Post-Operative Conditions. (1935) Bull N Y Acad Med 11(11): 639-656.

67. Henderson, Y. How Breathing Begins at Birth. (1937) Science 85(2195): 89-91.

68. Henderson, Y. Observations on RESUSCITATION FROM ASPHYXIA AND PREVENTION AND TREATMENT OF SECONDARY PNEUMONIA BY INHALATION OF CO2. (1931) Br Med J 2(3693): 687-689.

69. Jackson, D.E. Anesthesia Equipment From 1914 to 1954 and Experiments Leading To Its Development. (1955) Anesthesiology 16: 953969.

70. Lundy, J.S. Carbon Dioxide as an Aid In Anesthesia. (1925) JAMA $85: 1953$.

71. Lundy, J.S. Convulsions Associated with General Anesthesia. (1936) Mayo Clinic Health Letter.

72. Cassels WHB, T.J., Seevers, M.H. Convulsions During Anesthesia. (1938) American Society for Pharmacology and Experimental Therapeutics, Baltimore.

73. Seevers, M.C, WH; et al. The Role of Hypercapnia in the Production of "Ether Convulsions". (1938) J Pharmacol Exp Ther 63.

74. Waters, R.M. Carbon Dioxide Absorption from Anaesthetic Atmospheres : (Section of Anaesthetics). (1936) Proc R Soc Med 30(1): 1122.

75. Waters, R.M. Carbon Dioxide Absorption Technic in Anesthesia. (1936) Ann Surg 103(1): 38-45. 
76. Freidman, R.D. Carbon Dioxide in General Anesthesia. (1928) Dental Outlook June.

77. Lundy, J.S. Carbon Dioxide as an Aid In Anesthesia. (1925) JAMA 85: 1953.

78. Waters, R.M. Carbon Dioxide. (1938) Can Med Assoc J 38(3): 240243.

79. Sielenkamper, A.W., Eicker, K., Van Aken, H. Thoracic epidural anesthesia increases mucosal perfusion in ileum of rats. (2000) Anesthesiology 93(3): 844-851.

80. Kemp, W.N. The overuse of carbon dioxide absorption in general anesthesia. (1954) American journal of surgery 87(6): 864-868.

81. Beecher, H.K., Todd, D.P. A study of the deaths associated with anesthesia and surgery: based on a study of 599, 548 anesthesias in ten institutions 1948-1952, inclusive. (1954) Ann Surg 140(1): 2-35.

82. Brattwall, M., Warren-Stomberg, M., Hesselvik, F., et al. Brief review: Theory and practice of minimal fresh gas flow anesthesia. (2012) Can J Anaesth 59(8): 785-797.

83. Ladegaard-Pedersen, H.J. A Circle System without Carbon Dioxide Absorption. (1978) Acta Anaesth Scand 22(3): 281-286.

84. Eckenhoff, J.E. Carbon Dioxide and Man. (1960) Anesthesiology 21: 585-586.

85. Conlee, K.M., Stephens, M.L., Rowan, A.N., et al. Carbon dioxide for euthanasia: concerns regarding pain and distress, with special reference to mice and rats. (2005) Lab Anim 39(2): 137-161.

86. Danneman, P.J., Stein, S., Walshaw, S.O. Humane and practical implications of using carbon dioxide mixed with oxygen for anesthesia or euthanasia of rats. (1997) Lab anim sci 47(4): 376-385.

87. Thompson, CJSaHHH. A Forgotten pioneer of anesthesia. (1912) Brit Med J1:843-845.

88. Havill, J.H. Prolonged hyperventilation and intracranial pressure. (1984) Crit Care Med 12(1): 72-74.

89. Huttunen, J., Tolvanen, H., Heinonen, E., et al. Effects of voluntary hyperventilation on cortical sensory responses. Electroencephalographic and magnetoencephalographic studies. (1999) Exp Brain Res 125(3): 248-254.

90. Laffey, J.G., Engelberts, D., Duggan, M., et al. Carbon dioxide attenuates pulmonary impairment resulting from hyperventilation. (2003) Crit Care Med 31(11): 2634-2640.

91. Nishitateno, K., Ngai, S.H., Finck, A.D., et al. Pharmacokinetics of morphine: concentrations in the serum and brain of the dog during hyperventilation. (1979) Anesthesiology 50(6): 520-523.

92. Raichle, M.E., Plum, F. Hyperventilation and cerebral blood flow. (1972) Stroke 3(5): 566-575.

93. Salvatore, A.J., Sullivan, S.F, Papper, E.M. Postoperative hypoventilation and hypoxemia in man after hyperventilation. (1969) N Engl J Med 280(9): 467-470.

94. Taniguchi, A., Kitamura, S., Kawahara, R., et al. [Neonatal apnea after general anesthesia--effects of intraoperative hyperventilation and serum ionized Ca concentration]. (1995) Masui 44(4): 499-502.

95. van Hulst, R.A., Haitsma, J.J., Lameris, T.W., et al. Hyperventilation impairs brain function in acute cerebral air embolism in pigs. (2004) Intensive Care Med 30(5): 944-950.

96. Weckesser, M., Posse, S., Olthoff, U., et al. Functional imaging of the visual cortex with bold-contrast MRI: hyperventilation decreases signal response. (1999) Magn Reson Med 41(1): 213-216.

97. Overdyk, F.J. Postoperative opioids remain a serious patient safety threat. (2010) Anesthesiology 113(1): 259-260.

98. Forrest, W.H. Jr., Bellville, J.W. The Effect of Sleep Plus Morphine on the Respiratory Response to Carbon Dioxide. (1964) Anesthesiology 25: $137-141$.

99. Inoue, K., Takano, H., Yanagisawa, R., et al. Surgical stress in ARDS open-lung biopsy. (2004) Chest 126(4): 1383-1384.

100. Exadaktylos, A.K., Buggy, D.J., Moriarty, D.C., et al. Can anesthetic technique for primary breast cancer surgery affect recurrence or metastasis? (2006) Anesthesiology 105(4): 660-664.

101. Baum, M., Demicheli, R., Hrushesky, W., et al. Does surgery un- favourably perturb the "natural history" of early breast cancer by accelerating the appearance of distant metastases? (2005) Eur J Cancer 41(4): 508-515.

102. Jevtovic-Todorovic, V., Absalom, A.R., Blomgren, K., et al. Anaesthetic neurotoxicity and neuroplasticity: an expert group report and statement based on the BJA Salzburg Seminar. (2013) Br J Anaesth 111(2): 143-151.

103. Xie, Z., Dong, Y., Maeda, U., et al. The inhalation anesthetic isoflurane induces a vicious cycle of apoptosis and amyloid beta-protein accumulation. (2007) J Neurosci 27(6): 1247-1254.

104. Westmoreland, C.L., Sebel, P.S., Gropper, A. Fentanyl or alfentanil decreases the minimum alveolar anesthetic concentration of isoflurane in surgical patients. (1994) Anesth Analg 78(1): 23-28.

105. Brunner, M.D., Braithwaite, P., Jhaveri, R., et al. MAC reduction of isoflurane by sufentanil. (1994) Br J Anaesth 72(1): 42-46.

106. Smith, T.E., Elliott, W.G. Routine inhaled induction in adults: a safe practice? (2006) Anesth Analg 102(2): 646-647.

107. van den Berg, A.A., Chitty, D.A., Jones, R.D., et al. Intravenous or inhaled induction of anesthesia in adults?An audit of preoperative patient preferences. (2005) Anesth Analg 100(5): 1422-1424.

108. John, E.R., Prichep, L.S. The anesthetic cascade: a theory of how anesthesia suppresses Consciousness. (2005) Anesthesiology 102(2): 447-471.

109. Coleman, L. A Testable Stress Mechanism Explains Both Unified Stress Theory and Capillary Gate Theory. (2007) FDA Anesthesia \& Life Support Drugs Advisory Committee pp: 239-243 3/29/07.

110. Welty-Wolf, K.E., Carraway, M.S., Miller, D.L., et al. Coagulation blockade prevents sepsis-induced respiratory and renal failure in baboons. (2001) Am J Respir Crit Care Med 164(10): 1988-1996.

111. Kirkeby, O.J., Kutzsche, S., Risoe, C., et al. Cerebral nitric oxide concentration and microcirculation during hypercapnia, hypoxia, and high intracranial pressure in pigs. (2000) J Clin Neurosci 7(6): 531-538. 112. Smith, J.J, Lee, J.G., Hudetz, A.G., et al. The role of nitric oxide in the cerebrovascular response to hypercapnia. (1997) Anesth Analg 84(2): 363-369.

113. De Castro, G., Mundeleer, P. [Anesthesia without sleep: "neuroleptanalgesia”.]. (1959) Acta Chir Belg 58: 689-693.

114. de Castro, J., Van de Water, A., Wouters, L., et al. Comparative study of cardiovascular, neurological and metabolic side effects of 8 narcotics in dogs. Pethidine, piritramide, morphine, phenoperidine, fentanyl, R 39 209, sufentanil, R 34 995. III. Comparative study of the acute metabolic toxicity of the narcotics used in high and massive doses in curarised and mechanically ventilated dogs. (1979) Acta anaesthesiologica Belgica 30(1): 71-90.

115. Lowenstein, E., Hallowell, P., Levine, F.H., et al. Cardiovascular response to large doses of intravenous morphine in man. (1969) N Engl J Med 281: 1389-1393.

116. Leung, J.M., Goehner, P., O’Kelly, B.F., et al. Isoflurane anesthesia and myocardial ischemia: comparative risk versus sufentanil anesthesia in patients undergoing coronary artery bypass graft surgery. The SPI (Study of Perioperative Ischemia) Research Group. (1991) Anesthesiology 74(5): 838-847.

117. Ohmura, A., Sha, M., Katagiri, J. How far can we go with permissive hypercapnia? A case presentation and some biased comments with emphasis on maintaining normal haemoglobin level. (1995) Acta Anaesthesiol Scand Suppl 107: 209-213.

118. Hickling, K.G., Henderson, S.J., Jackson, R. Low mortality associated with low volume pressure limited ventilation with permissive hypercapnia in severe adult respiratory distress syndrome. (1990) Intensive Care Med 16(6): 372-377.

119. Bellville, J.W.S., John, C. The Effect of Drugs on the Respiratory Response to Carbon Dioxide. (1960) Anesthesiology 21: 727-741.

120. Marquez, J., Magovern, J., Kaplan, P., et al. Cardiac surgery "fast tracking" in an academic hospital. (1995) J Cardiothorac Vasc Anesth 9(5): 34-36.

121. Tuman, K.J., McCarthy, R.J., Spiess, B.D., et al. Does choice of 
anesthetic agent significantly affect outcome after coronary artery surgery? (1989) Anesthesiology 70(2): 189-198.

122. Bissonnette, B., Swan, H., Ravussin, P., et al. Neuroleptanesthesia: current status. (1999) Can J Anaesth 46(2): 154-168.

123. Davies, M.G., Hagen, P.O. Systemic inflammatory response syndrome. (1997) Br J Surg 84(7): 920-935.

124. Liu, Y.G., Li, C.S. [Coagulation dysfunctions in patients with systemic inflammatory response syndrome]. (2004) Zhonghua Nei Ke Za Zhi 43(2): 94-97.

125. Takenaka, K., Ogawa, E., Wada, H., et al. Systemic inflammatory response syndrome and surgical stress in thoracic surgery. (2006) J Crit Care 21(1): 48-53.

126. Shavit, Y., Ben-Eliyahu, S., Zeidel, A., et al. Effects of fentanyl on natural killer cell activity and on resistance to tumor metastasis in rats. Dose and timing study. (2004) Neuroimmunomodulation 11(4): 255-260.

127. Sessler, D.I. Does regional analgesia reduce the risk of cancer recurrence?A hypothesis. (2008) European journal of cancer prevention 17(3): 269-272.

128. Benumof , J.L. Management of the difficult adult airway.With special emphasis on awake tracheal intubation. (1991) Anesthesiology 75(6): 1087-1110.

129. Benumof, J.L. Awake intubations are alive and well. (2015) Can J Anaesth 62(7): 723-726.

130. Coleman, S.A., McCrory, J.W., Vallis, C.J., et al. Inhalation induction of anaesthesia with isoflurane: effect of added carbon dioxide. (1991) Br J Anaesth 67(3): 257-261.

131. Coleman, L.S. A testable hypothesis that may explain the morbidity and mortality caused by surgical stress. (2006) Anesth Analg 103(6): 1589-1590.

132. Laster, M.J., Eger, E.I. 2nd. Temperatures in soda lime during degradation of desflurane, isoflurane, and sevoflurane by desiccated soda lime. (2005) Anesth Analg 101(3): 753-757.

133. Coleman, L.S. Should soda lime be abolished? (2006) Anesth Analg 102(4): 1290-1291.
134. Keijzer, C., Perez, R.S., De Lange, J.J. Carbon monoxide production from five volatile anesthetics in dry sodalime in a patient model: halothane and sevoflurane do produce carbon monoxide; temperature is a poor predictor of carbon monoxide production. (2005) BMC Anesthesiol 5(1): 6 .

135. Moriwaki, G., Bito, H., Ikeda, K. Partly exhausted soda lime or soda lime with water added, inhibits the increase in compound A concentration in the circle system during low-flow sevoflurane anaesthesia. (1997) Br J Anaesth 79(6): 782-786.

136. Schoonbee, C.G., Conway, C.M. Factors affecting carbon dioxide homeostasis during controlled ventilation with circle systems. (1981) Br J Anaesth 53(5): 471-477.

137. Coleman, L.S. A Stress Repair Mechanism that Maintains Vertebrate Structure during Stress. (2010) Cardiovasc Hematol Disord Drug Targets 10(2): 111-137.

138. Mangano, D.T, Hollenberg, M., Fegert, G., et al. Perioperative myocardial ischemia in patients undergoing noncardiac surgery--I: Incidence and severity during the 4 day perioperative period. The Study of Perioperative Ischemia (SPI) Research Group. (1991) J Am Coll Cardiol 17(4): 843-850.

139. Ben-Shlomo, I., Finger, J., Bar-Av, E., et al. Propofol and fentanyl act additively for induction of anaesthesia. (1993) Anaesthesia 48: 111113.

140. McEwan, A.I., Smith, C., Dyar, O., et al. Isoflurane minimum alveolar concentration reduction by fentanyl. (1993) Anesthesiology 78(5): 864-869.

141. Thome, U.H., Carlo, W.A. Permissive hypercapnia. (2002) Semin Neonatol 7(5): 409-419.

142. Zhou, Q., Cao, B., Niu, L., et al. Effects of permissive hypercapnia on transient global cerebral ischemia-reperfusion injury in rats. (2010) Anesthesiology 112(2): 288-297.
Ommega Online Publishers

Journal Title: Journal of Anesthesia and Surgery (JAS)

Journal Short Name: J Anesth Surg
Journal ISSN: 2377-1364

E-mail: anestheisa@ommegaonline.com

Website: www.ommegaonline.org 